\title{
Natural Occurrence of Maize Gibberella Ear Rot and Contamination of Grain with Mycotoxins in Association with Weather Variables
}

\author{
F. Dalla Lana, L. V. Madden, and P. A. Paul ${ }^{\dagger}$ \\ Department of Plant Pathology, The Ohio State University, Ohio Agricultural Research and Development Center, Wooster, OH \\ 44691
}

Abstract

\begin{abstract}
Gibberella ear rot (GER) severity (percent area of the ear diseased) and associated grain contamination with mycotoxins were quantified in plots of 15 to 16 maize hybrids planted at 10 Ohio locations from 2015 to 2018. Deoxynivalenol (DON) was quantified in grain samples in all 4 years, whereas nivalenol, 3-acetyldeoxynivalenol, and 15-acetyldeoxynivalenol $(15 \mathrm{ADON})$ were quantified only in the last 2 years. Only DON and 15ADON were detected. The highest levels of GER and DON contamination were observed for 2018, followed by 2016 and 2017. No GER symptoms or DON were detected in 2015 . Approximately $41 \%$ of the samples from asymptomatic ears had detectable levels of DON, and $7 \%$ of these samples from 2016 had DON $>5 \mathrm{ppm}$. Associations between DON contamination and 43 variables representing summaries of temperature $(\mathrm{T})$, relative humidity $(\mathrm{RH})$, rainfall $(\mathrm{R})$, surface wetness, and T-RH combinations for different window lengths and positions relative to $\mathrm{R} 1$
\end{abstract}

growth stage were quantified with Spearman correlation coefficients $(r)$. Fifteen-day window lengths tended to show the highest correlations. Most of the variables based on T, R, RH, and T-RH were significantly correlated with DON for the 15-day window, as well as other windows. For moisturerelated variables, there generally was a negative correlation before R1, changing to a positive correlation after R1. Results showed that GER and DON can be frequently found in Ohio maize fields, with the risk of DON being associated with multiple weather variables, particularly those representing combinations of $\mathrm{T}$ between 15 and $30^{\circ} \mathrm{C}$ and $\mathrm{RH}>80$ summarized during the 3 weeks after R1.

Keywords: cereals and grains, climate/weather effects, correlation analysis, epidemiology, disease development and spread, field crops, window-pane analysis
Gibberella ear rot (GER), caused by members of the Fusarium graminearum species complex, has become the most frequently occurring and important ear disease of maize in Ohio and other states in the U.S. Midwest (Koehler 1959; Mueller et al. 2016), as well as in parts of the Canadian provinces of Ontario, Quebec, and Manitoba (Albert Tenuta, personal communication). Infection and disease development are complex processes that affect the way symptoms are manifested (Sutton et al. 1980). Typically, the fungus enters the ear via the silks, leading to the characteristic symptoms of whitish to reddish mold that starts at the tip of the ear and spreads downward. However, it is not uncommon for infections to occur at the base of the ear and spread toward the tip. This is particularly common when ears dry-down in an upright position and extended periods of wet, rainy conditions persist late in the season. Infections may also occur via wounds made by birds, insects, or hail, leading to disease development and spread from wherever the initial damage occurred. On severely diseased ears, husk leaves become tightly attached to the kernels and often die prematurely. Under persistently wet conditions, perithecia are produced on the dead husk leaves, giving the surface of the ear a dark, dusty appearance (Munkvold and White 2016; Sutton 1982).

${ }^{\dagger}$ Corresponding author: P. A. Paul; paul.661@osu.edu

Funding: This project was supported by funding from the Ohio Corn and Wheat Growers Association, the United States Department of AgricultureNational Institute of Food and Agriculture (award number 2014-7000622507), Bayer CropScience, and The Ohio State University Department of Plant Pathology. Salaries and research support for F. Dalla Lana, L. V. Madden, and P. A. Paul were provided by state and federal funds to the Ohio Agricultural Research and Development Center.

*The $\boldsymbol{e}$-Xtra logo stands for "electronic extra" and indicates that supplementary materials are published online.

The author(s) declare no conflict of interest.

Accepted for publication 8 July 2020

(C) 2021 The American Phytopathological Society
Under conditions favorable for GER development, yield loss may be close to $50 \%$ when susceptible hybrids are planted (Vigier et al. 2001); however, the greatest economic impact of this disease stems from the contamination of grain with mycotoxins produced by $F$. graminearum (Sutton 1982). Zearalenone, nivalenol (NIV), deoxynivalenol (DON), and its acetylated derivatives 3-acetyldeoxynivalenol (3ADON) and 15-acetyldeoxynivalenol (15ADON) are the most commonly detected toxins in GER-affected ears (Desjardins 2006; Papst et al. 2001; Placinta et al. 1999). These trichothecenes are reported to be virulence factors in the development of GER (Harris et al. 1999) and Fusarium head blight (FHB) (Bai et al. 2002), a disease of wheat and other small grain crops that is caused by the same pathogen (Sutton 1982). In both pathosystems, non-DONproducing isolates of the fungus were able to infect and cause disease but colonization and, consequently, disease severity was considerably lower on ears or spikes infected with non-DON-producing isolates compared with those infected with DON-producing isolates (Bai et al. 2002; Cossette and Miller 1995; Foroud and Eudes 2009; Harris et al. 1999; Ismaiel and Papenbrock 2015). Disease severity and mycotoxin contamination may also be affected by the chemotype of the pathogen. In some studies with inoculated wheat and barley, $3 \mathrm{ADON}$-producing isolates of $F$. graminearum were reported to be more aggressive and produce more DON than 15ADON-producing isolates (Foroud et al. 2012; Puri and Zhong 2010; ValverdeBogantes et al. 2019; Ward et al. 2008). However, this type of pathogenic fitness advantage was not observed with the $3 \mathrm{ADON}$-producing chemotype in other studies (Kuhnem et al. 2015; Spolti et al. 2014).

Mycotoxins may have deleterious effects on human and animal health. For instance, trichothecenes such as DON affect the immune system and physiological processes by inhibiting ribosomal protein synthesis (Desjardins 2006). Common clinical symptoms of mycotoxin poisoning (mycotoxicosis) in animals include weight loss, nausea, diarrhea, feed refusal, and vomiting (Edite Bezerra da Rocha et al. 2014). To reduce the risk of DON and other mycotoxins entering the food chain, grain buyers often apply price penalties or reject grain lots with mycotoxin contamination above certain thresholds. Consequently, entire grain loads may be deemed of low market value, leading to economic losses. Quite often, producers have no 
way of telling beforehand whether their grain is contaminated because mycotoxins may accumulate in healthy-looking ears and grain (Reid et al. 1996). DON contamination also has an economic impact on the ethanol industry because it affects the quality and commercial value of dried distiller's grains with solubles (DDGS), a coproduct of ethanol production that is sold for use in livestock feed. During the ethanol production process, DON becomes concentrated in DDGS to levels three times higher than in the original grain (Schaafsma et al. 2009). Consequently, grain lots with relatively low DON contamination may still yield DDGS with unacceptably high levels of the toxin, limiting its use as a feed ingredient.

GER is usually thought of as a disease that is favored by cool, wet conditions (Munkvold 2003; Munkvold and White 2016; Sutton 1982); more specifically, moisture during silking, rainfall during grain development and harvest (Munkvold 2003; Sutton 1982), and temperatures ranging from below $22^{\circ} \mathrm{C}$ (Sutton 1982) to $28^{\circ} \mathrm{C}$ (Reid et al. 1999). However, with few exceptions, most of these assumptions were based on anecdotal field observations (Miller 1994), without confirmation through designed experiments (Sutton 1982) or quantitative assessments of associations between specific weather variables and GER intensity. Observations from recent outbreaks suggest that the optimum conditions for GER development, and for DON accumulation in particular, are not as clearly defined. As discussed by De Wolf and Paul (2014), due to complex interactions among host, pathogen, and the environment, conditions that are ideal for visual symptom development may be somewhat different from those favorable for mycotoxin accumulation. Studying the epidemiology of FHB of wheat, Shah et al. (2019a) and Kriss et al. (2010, 2012) demonstrated that the strength of associations between weather and disease severity depended on the specific weather variable and how it was summarized relative to the crop growth stage of greatest susceptibility to infection. Similar types of research are needed to better understand associations among weather summaries, GER development, and DON contamination.

As alluded to by Munkvold (2003), the lack of specific information pertaining to the influence of environmental conditions on infection, disease development, and mycotoxin accumulation in the $F$. graminearum-maize pathosystem has made it difficult to develop risk-assessment models similar to those developed for FHB and DON in wheat (De Wolf et al. 2003; Hooker et al. 2002). The objectives of this study were to (i) monitor naturally occurring GER epidemics and mycotoxin contamination of grain in 10 locations representing distinct maize production regions in Ohio over a 4-year period, (ii) determine the type-B trichothecene profile of $F$. graminearum infecting maize, and (iii) quantify associations between summary weather variables and DON contamination of grain, with emphasis on identifying the number of days and periods relative to growth stage R1 with the strongest associations. To achieve these objectives, hybrids with different levels of resistance to GER were planted at the 10 locations in each of the 4 years, rated for GER, and tested for mycotoxin contamination of grain. Weather data were also collected at each location, summarized using the window-pane method (Coakley et al. 1985), and correlated with GER severity and DON contamination. The window-pane analysis is a type of data-mining algorithm that is used to summarize continuous weather variables into discrete periods (windows) with fixed starting and ending points relative to crop growth stages (Kriss et al. 2010). After being introduced by Coakley et al. (1985) in the 1980s, window-pane analysis has been used extensively in plant pathology to quantify associations between weather variables and disease intensity (Calvero et al. 2003; Coakley et al. 1988; Francl et al. 1990; Kriss et al. 2010, 2012; Molitor et al. 2016; Pietravalle et al. 2003; Te Beest et al. 2008; Xu et al. 2019).

\section{Materials and Methods}

Plot establishment and GER and DON data collection. Field plots were established in 2015, 2016, 2017, and 2018 at 10 locations across Ohio (Fig. 1), for a total of 40 unique environments. Each location represented a distinct production region in terms of total maize acreage, cropping practices, and soil regions (Barker et al. 2017; Minyo et al. 2015, 2016, 2017, 2018). A single four-row plot (7.6 by $3.0 \mathrm{~m}$ ) of each of 15 to 16 (105- to 113-day maturity) hybrids was planted at each location between 8 and 23 May 2015, 7 and 26 May 2016, 15 May and 2 June 2017, and 8 and 26 May 2018, at a density of 84,000 plants/ha. One hybrid (Pioneer brand P1360AM) was classified as susceptible based on the company classification (3 on a 1-to-9 scale, where 9 is most resistant) (Pioneer 2014) and results from previous inoculated studies (Dalla Lana et al. 2016). The other 14 to 15 hybrids were randomly selected from a poll of more than 60 hybrids that were included in the 2015 Ohio Corn Performance Trial (Minyo et al. 2015, 2016, 2017, 2018). In total, 10 hybrids, including the standard susceptible, were planted in all 4 years, but 5 of the 15 planted in 2015 were replaced in the last 3 years because seeds were no longer available. In addition, a 16th hybrid was included in the study in 2017 and 2018. All selected hybrids carried transgenic traits for insect control. Tillage, pesticide application, and other agronomic practices followed standard recommendations for each production region (Barker et al. 2017; Minyo et al. 2015, 2016, 2017, 2018).

Crop development was monitored throughout the growing season in each environment, and the date on which each hybrid reached the R1 (silking) growth stage (Abendroth et al. 2011) was recorded. In total, 5 (2015) or 10 (2016 to 2018) arbitrarily selected primary ears were hand harvested from each plot at physiological maturity (blacklayer-combine-harvested grain moisture was below approximately $20 \%$ ), transported to the laboratory, husked, and then maintained in a greenhouse to air dry (to grain moisture of approximately $10 \%$ ) until processed. Each ear was individually rated for GER severity as percent surface area covered with characteristic symptoms of the disease. Ears were shelled manually, and a subsample of $40 \mathrm{~cm}^{3}$ of grain was collected using a $20-\mathrm{cm}^{3}$ laboratory measuring spoon and pooled into a composite sample per plot (approximately $400 \mathrm{~cm}^{3}$ ). A portion of approximately $40 \mathrm{~g}$ of each thoroughly mixed composite sample was ground to flour using a laboratory mill (Model LM 3303; Perten Instruments Inc., Springfield, IL, U.S.A.), and a sample

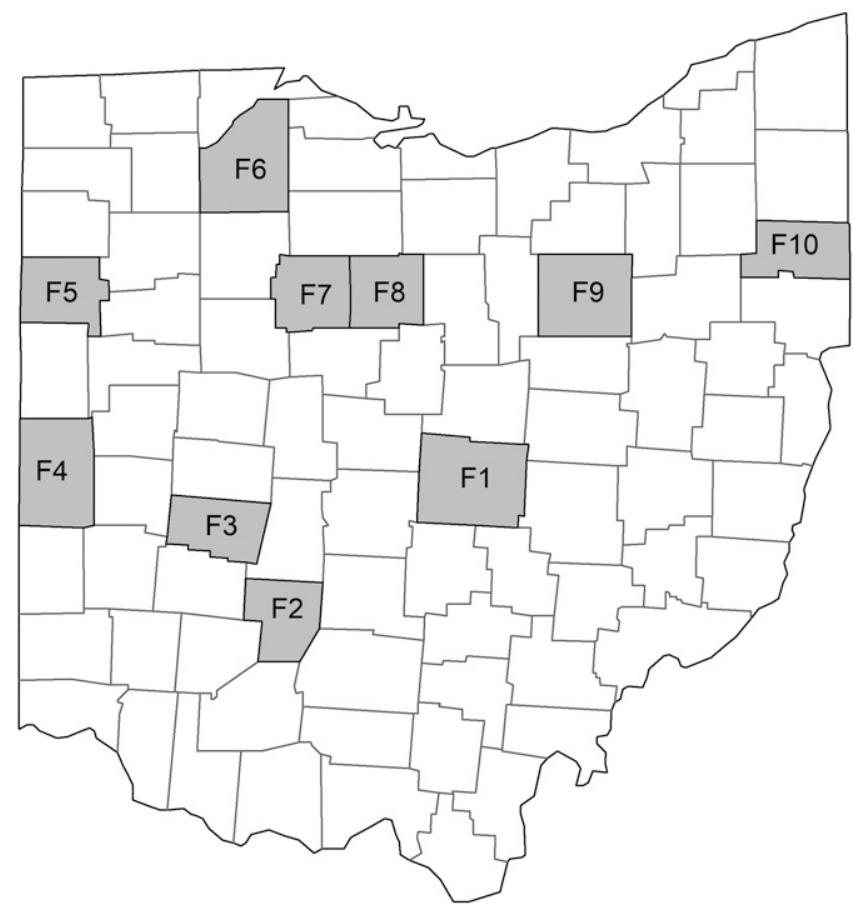

Fig. 1. Map of Ohio showing the counties in which plots were established during the 2015, 2016, 2017, and 2018 growing seasons to monitor the development of Gibberella ear rot of maize, deoxynivalenol (DON) mycotoxin contamination of grain, and associated weather conditions. F1 = Licking County, F2 = Fayette County, F3 = Clark County, F4 = Darke County, F5 = Van Wert County, F6 = Wood County, F7 = Wyandot County, F8 = Crawford County, F9 = Wayne County, and F10 = Mahoning County. Most of the acreage for maize is in the central to western half of the state. 
Table 1. Abbreviations and descriptions of daily weather variables used in the window-pane analysis

\begin{tabular}{|c|c|}
\hline Abbreviation & Description \\
\hline \multicolumn{2}{|l|}{ Rain (R) } \\
\hline R.AH & Hours with rain (hour) \\
\hline R.PA & Rain $($ Yes/No) \\
\hline R.S & Total precipitation $(\mathrm{mm})$ \\
\hline \multicolumn{2}{|c|}{$\begin{array}{l}\text { Relative humidity } \\
\text { (RH) }\end{array}$} \\
\hline RH.A & Mean RH (\%) \\
\hline RH.min & Minimum RH (\%) \\
\hline RH.max & Maximum RH (\%) \\
\hline RH.RH80 & Number of hours with $\mathrm{RH} \geq 80 \%$ \\
\hline RH.RH90 & Number of hours with $\mathrm{RH} \geq 90 \%$ \\
\hline RH.80.rl.count6 & At least $6 \mathrm{~h}$ with $\mathrm{RH} \geq 80 \%(\mathrm{Yes} / \mathrm{No})$ \\
\hline RH.90.rl.count6 & At least $6 \mathrm{~h}$ with $\mathrm{RH} \geq 90 \%(\mathrm{Yes} / \mathrm{No})$ \\
\hline RH.80.rl.max & $\begin{array}{l}\text { Maximum number of consecutive hours with } \\
\mathrm{RH} \geq 80 \%\end{array}$ \\
\hline RH.90.rl.max & $\begin{array}{l}\text { Maximum number of consecutive hours with } \\
\mathrm{RH} \geq 90 \%\end{array}$ \\
\hline RH.80.rl.wind6 & $\begin{array}{l}\text { Number of periods with at least } 6 \text { consecutive } \\
\text { hours with } \mathrm{RH} \geq 80 \%\end{array}$ \\
\hline RH.90.rl.wind6 & $\begin{array}{l}\text { Number of periods with at least } 6 \text { consecutive } \\
\text { hours with } \mathrm{RH} \geq 90 \%\end{array}$ \\
\hline
\end{tabular}

\section{$(\mathbf{W E})^{\mathrm{a}}$}

WE.A

WE.WE70

WE.WE80

WE.WE90

Temperature (T)

T.A

T.min

T.max

T.L9

T.L15

T.L20

T.L23

T.L25

T.L30

T.G15

T.G20

T.G23

T.G25

T.G30

T.9T30

T.15T30

T.20T30

T.25T33

GDD $^{\mathrm{b}}$

T and RH (TRH)

TRH.15T30nRH80

TRH.15T30nRH90

TRH.9T30nRH80

TRH.9T30nRH90

Others

DPD $^{\mathrm{c}}$

$\mathrm{VPD}^{\mathrm{d}}$ of approximately $20 \mathrm{~g}$ of the ground grain was pulled for mycotoxin analysis. Samples were processed (shelled, mixed, subsampled, and ground) beginning with those from plots with the lowest to the highest mean GER severity, and all processing utensils were thoroughly cleaned between samples to minimize cross contamination.

In 2015, the year in which no visual symptoms of GER were observed on any of the ears inspected, samples were tested inhouse for DON using a lateral-flow immunochromatographic quick-test kit (Reveal Q+ for DON; NEOGEN, Lansing, MI, U.S.A.), following the manufacturer's instructions. The limit of detection (LOD) was $0.3 \mathrm{ppm}$. Samples collected in 2016, 2017, and 2018 were shipped to a mycotoxin testing laboratory at the University of Minnesota for DON analysis by gas chromatography-mass spectrometry (GCMS) (Salgado et al. 2011). Additionally, samples from 2017 and 2018 were tested for NIV, 3ADON, and 15ADON by GC-MS, with an LOD of $0.05 \mathrm{ppm}$ for all toxins. Quick-tests are faster and cheaper than GC-MS and, as such, suitable for rapid initial mycotoxin screening (Astoreca et al. 2017), particularly when samples are not obviously infected and contaminated, as was the case in 2015. However, several quick-test kits, including the one used here in 2015 (Reveal Q+), are approved by the United States Department of Agriculture-Federal Grain Inspection Service (USDA-FGIS 2018) for routine DON testing. van der Fels-Klerx and de Rijk (2014) reported that Reveal Q+ was an accurate and reliable test for DON in different wheat samples spiked with known concentrations of the toxin. For samples with mycotoxin test results below the LOD, contamination was assumed to be $0 \mathrm{ppm}$ in subsequent data analysis.

Weather variables associated with DON contamination of grain. Weather data collection and organization. A weather station equipped with a rain gauge (Model S-RGB-M002; Onset Computer Corporation) and sensors to monitor surface wetness (Model S-LWA-M003; Onset Computer Corporation), temperature, and relative humidity (Model S-THB-M002; Onset Computer Corporation) was installed at each location to collect meteorological data at 5- to 15-min intervals from 7 to 45 days after planting until harvest. Based on previous studies on FHB of wheat (De Wolf et al. 2003; Kriss et al. 2010, 2012; Shah et al. 2013, 2014, 2019a), 43 summary weather variables were generated for each day from temperature $\left(\mathrm{T},{ }^{\circ} \mathrm{C}\right)$, relative humidity $(\mathrm{RH}, \%)$, rainfall $(\mathrm{R}, \mathrm{mm})$ and surface wetness (WE, \%). These variables are described in detail in Table 1 but, in brief, they represent simple summaries such as means, minima, and maxima; cumulative summaries such as number of hours within specific ranges or above certain cutoff values; combinations such as number of hours with $\mathrm{T}$ between specific ranges and $\mathrm{RH}$ above certain cutoff values; and weather indices such as dew point depression and vapor pressure deficit (VPD). These were generated for daily or daylong (24-h) and nighttime (12-h; 2000 to $0800 \mathrm{~h}$ ) periods, resulting in 86 weather variables being created for each environment (location-year) (Table 1).

Window-pane analysis: construction of weather variable. The window-pane analysis was performed as a two-stage process, with the first stage being the generation of summary environment variables for fixed time periods called windows, beginning and ending at specific times relative to a specific crop growth stage; and the second consisting of correlation analyses of associations between some disease- or toxin-related variable and each summary weather variable. In this study, we used silking (R1) as our reference growth stage. For the first stage of the analysis, the variables in Table 1 were summarized as averages or summations for window lengths of 5,10 , $15,20,25$, and 30 days. Beginning at 60 days after R1, each window was shifted backward in daily time steps, with the summary generated at each step, until the last possible step is reached at 30 days before R1. The total time frame was 91 days. For instance, for daily mean T (T.A) with a 20-day window length starting on 30 August, the summary value for the first window was the mean T.A from 30 to 11 August, the second window was then moved back by a day and the mean was calculated from 29 to 10 August, the third window as then shifted back by an additional day and the mean was calculated from 28 to 9 August, and so on until the end of the time frame.

Window-pane analysis: correlations between weather variables and DON. Given the relationship commonly found between GER 
and DON (Reid and Sinha 1998; Reid et al. 1996) and the fact that DON is often considered more economically important than GER, we limited our window-pane analyses to relationships between DON and the weather variables to reduce redundancy in the presentation of the results. Also, we limited our window-pane analysis to the standard susceptible hybrid, P1360AM, to avoid the effect of hybrid resistance and other traits on the correlations (F. Dalla Lana, unpublished). To quantify associations between each summary weather variable and DON contamination in the second stage of the windowpane analysis, we calculated Spearman rank correlation coefficients ( $r) ; 1,000$ bootstrap samples using the boot function from the R package of the same name (version 1.3-23) were calculated to quantify precision of the correlations. The Spearman correlation quantifies the strength of the monotonic relationship between pairs of variables (rather than a simple linear relationship) and is insensitive to outliers for either variable in the pair. Individual observations (defined here as unique combinations of field location and year [environment], with DON contamination and associated weather summaries as the analyzed variables) were randomly drawn with replacement from the the original dataset until a bootstrap sample of the same size as the original population was obtained. Correlation coefficients were then calculated for each DON-weather variable combination for each bootstrap sample, and means were estimated across the 1,000 samples as measures of association.

Analyses of the type proposed here that involve a large number of test statistics are subject to the issue of multiple hypothesis testing. Kriss et al. (2010) discussed reasons for and consequences of this problem in window-pane analysis, and proposed several approaches for addressing the same. For instance, for the 30-day window length, there are 61 windows over the 91-day time frame, each with an estimated correlation coefficient for a given weather variable. With this many coefficients, estimated using data from different but overlapping windows, there is a higher than nominal chance of falsely declaring one or more of them as being statistically significant for a selected $\alpha$ significance level. To reduce this and other related multiplicity problems, we performed a global test of significance across all starting times for each weather variable and window length using the Simes method (Simes 1986) as described by Kriss et al. (2010, 2012). This method tests the null hypothesis $\left(H_{O(g)}\right)$ that none of the individual correlations in a set are statistically significant against the alternative hypothesis $\left(H_{a(g)}\right)$ that at least one correlation is different from 0 . With the Simes test, individual $P$ values from correlations at each of the $k$ windows were ordered from lowest to highest, and the $j$ th smallest individual $P$ values $\left(P_{j}\right)$ were used to obtain adjusted $P_{j}$ values $\left(\tilde{P}_{j}\right)$ and, from them, global $P$ values $\left(P_{g}\right)$ as detailed by Kriss et al. (2010). Values of $P_{g}<0.05$ were considered statistically significant, meaning that at least one of the correlation coefficients was different from zero (reject $H_{0(g)}$ ).

Data organization, analyses, and graphing were done using $\mathrm{R}$ for Windows 10 (version 3.7.0) (R Core Team 2019). Several add-on packages were used, including tidyverse (version 1.2.1) (Wickham et al. 2019) for data organization and graphs, boot (version 1.3-23) (Canty and Ripley 2019) for bootstrap resampling, and the cor.test function from the stats package (version 3.7.0) (R Core Team 2019) for correlation analysis.

\section{Results}

General growing conditions, GER development, and mycotoxin contamination. Silking (R1), used here as the reference growth stage, ranged from 22 to 30 July 2015, 18 July to 8 August 2016, 20 July to 11 August 2017, and 10 July to 7 August 2018. Southern locations (F1 to F4) tended to reach R1 earlier than more northern locations (F5 to F10) in the state. In general, the 30 days before R1 were wetter and cooler in 2015 than in the other three growing seasons. Averaged across the 10 fields, the mean number of hours with rain was 57 in 2015, with 18 to $37 \mathrm{~h}$ fewer in 2016 (20 h), 2017 (39 h), and 2018 (33 h). However, for the period of 1 month after R1, the mean number of hours with rain dropped to 22 in 2015 and 27 in 2017 but increased to 48 and $50 \mathrm{~h}$ in 2016 and 2018, respectively. Not only was rainfall during the 30 days after R1 more frequent in 2016 and
2018 than in 2015 and 2017, the total amount of rain was also greater; $1,074 \mathrm{~mm}$ in 2016 and $1,146 \mathrm{~mm}$ in 2018 , compared with $556 \mathrm{~mm}$ in 2015 and $650 \mathrm{~mm}$ in 2017 . For the same 30 -day post-R 1 period, mean T was 2.6 to $3.7^{\circ} \mathrm{C}$ warmer in 2016 than in 2015 and 2017 and 1.2 to $2.4^{\circ} \mathrm{C}$ warmer in 2018 than in the second and third years of the study. More detailed tabulated and graphical field-by-field and year-by-year presentations of the raw weather data are shown in the Supplementary Table S1 and Supplementary Figures S1 to S5.

There was considerable variation in GER intensity and DON contamination among seasons, fields within seasons, and among hybrids in any given field. Mean GER severity was highest in 2018, followed by 2016 and 2017, and lowest at 2015, with ranges among the hybrids of 0 to 12,0 to 16.7 , and 0.8 to $22.4 \%$, in 2016, 2017, and 2018, respectively (Fig. 2A, C, and E). All inspected ears were asymptomatic in all 10 fields in 2015, in 2 fields in 2017 (F3 and F8), and 1 field in 2018 (F2). Thus, the results are not shown for 2015 in Figure 2. The distribution of mean GER severity across hybrids also varied among fields and years. For instance, in F7, the interquartile range (IQR) for mean severity was $5.0 \%$ in 2018 , compared with 0 in 2016 and 2017. Among fields in 2018, the IQR was considerable higher in F7, F6, F8, and F10 (1.5 to 5.0\%) compared with the other six fields ( 0.0 to $0.5 \%)$. The absence of visual evidence of insect or bird damage on the inspected ears and the fact that the diseased kernels were clustered toward the tip of the ear suggested that infections likely occurred predominantly via the silk channel. Data were missing for three plots or hybrids in 2016, one hybrid in F3, and two hybrids in F9.

Trends in terms of peaks and variability in DON accumulation in harvested grain among the hybrids, fields, and years were comparable with those observed for visual symptoms of GER (Fig. 2B, D, and F). Natural levels of DON contamination ranged from 0 to $46.1 \mathrm{ppm}$, with a mean of $4.5 \mathrm{ppm}$, in 2018 compared with 0 to $56.7 \mathrm{ppm}$, with a mean of $3.0 \mathrm{ppm}$, in 2016 and 0 to $34.9 \mathrm{ppm}$, with a mean of $0.9 \mathrm{ppm}$, in 2017. However, mean DON was consistently higher across fields in 2016 than in 2017 and 2018, except for F4, F6, F7, and F8 that had higher mean levels of the toxin in 2018 than in 2016 (Fig. 2B, D, and F). In 2015, DON contamination was below the detectable limit of 0.3 ppm across all hybrids and locations (the quantification method in 2015 had a higher detection limit than for the other years). The mean level of grain contamination with DON was much more variable in 2018 (Fig. 2F), with an IQR of 3.6 ppm, than in 2016 (Fig. 2B) and 2017 (Fig. 2D), with IQR values of 2.3 and 1.4 ppm, respectively.

Not only was mean DON contamination higher in 2016 and 2018 than in 2015 and 2017, a significant percentage (18 and 21\%) of the total samples collected in these 2 years had DON contamination above the regulatory advisory limit (Khatibi et al. 2014) of 5 ppm (Fig. 3A), and an additional 25.9 and $19.4 \%$ had DON between 1 and $5 \mathrm{ppm}$ in 2016 and 2018, respectively. In 2016, approximately $7 \%$ of the grain samples from ears without visual symptoms of GER had DON contamination above $5 \mathrm{ppm}$ (Fig. 3B). Of the 483 asymptomatic samples tested over the 4 years, 196 (approximately $41 \%$ ) had detectable levels of DON and 46 (approximately 10\%) had DON between 1 and 5 ppm. An even higher percentage of the asymptomatic samples, 81 and $68 \%$, tested positive for DON in 2016 and 2018, respectively, compared with $33 \%$ in 2017 and $0 \%$ in 2015. In 2016, 2017, and 2018, approximately, 27,5 , and $8 \%$, respectively, of the samples from asymptomatic ears had DON contamination between 1 and 5 ppm.

Results from analyses of the type B trichothecene (DON, 3ADON, $15 \mathrm{ADON}$, and NIV) profile of the 320 samples collected during the 2017 and 2018 growing seasons showed that 15ADON was present in $54.7 \%$ of the samples, with levels of contamination ranging from 0 to $2.5 \mathrm{ppm}$ (mean 0.06) and 0 to $3.9 \mathrm{ppm}$ (mean 0.62) in 2017 and 2018 , respectively. This DON derivative was detected in all tested fields in 2018 and in all but one (F9) tested field in 2017, with the highest mean levels of contamination in F1 $(0.17 \mathrm{ppm}), \mathrm{F} 2(0.19$ ppm), F4 (0.15 ppm), and F10 (0.25 ppm) in 2017; and F6 (0.71 ppm), F7 (2.32 ppm), F8 (0.49 ppm), and F10 (0.36 ppm) in 2018. Results from Spearman rank correlation coefficients showed a strong positive association between $15 \mathrm{ADON}$ and DON, with correlation coefficients of $0.89(n=160, P<0.001)$ and $0.96(n=160$, 
$P<0.001)$ in 2017 and 2018, respectively. Neither NIV nor 3ADON were detected in the samples analyzed.

Window-pain analysis. Summary weather variables. For each day during the 91-day time frame, 43 weather variables were generated from the original raw weather data (Table 1) for both daylong periods and nighttime periods. Of these, 3 were R-related, 11 were related to RH only, 18 represented T alone, 4 were WE-related, 4 represented T-RH combinations, and 1 each related to dew point depression, VPD, and growing degree days (GDD). For each of these variables, 882 summaries were generated over the 91-day time frame for daylong and nighttime (12-h) periods (each variable over all the window lengths that all shifted in daily increments), which was a composite of 172 for the 5-day window length, 162 for the 10-day window length, 152 for the 15-day window length, and 142, 132, and 122 for the 20-, 25-, and 30-day window lengths, respectively. Altogether, there were 37,926 weather summaries, of which 22,446 represented conditions entirely after R1 (post-R1), 6,450 represented conditions entirely before $\mathrm{R} 1$ (pre-R1), and the remaining 9,030 summarized conditions during as well as before or after R1.

Associations between DON contamination and summary weather variables. Spearman rank correlation coefficients $(r)$ for associations between DON contamination of grain and weather summaries across
A 2016

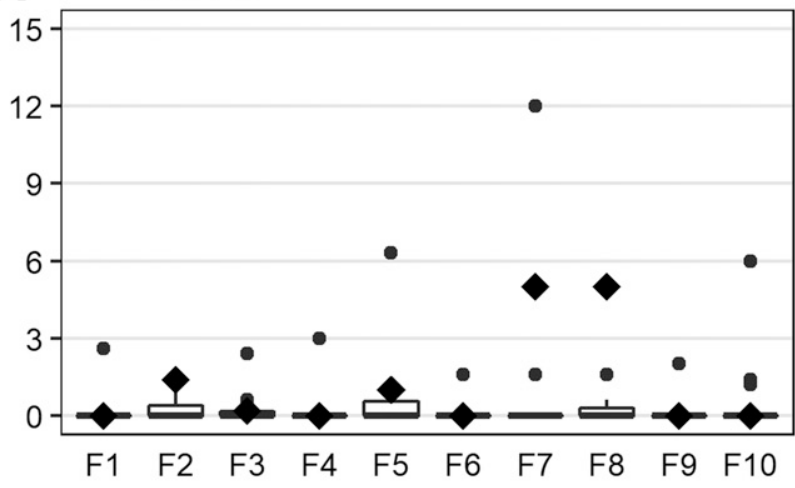

C

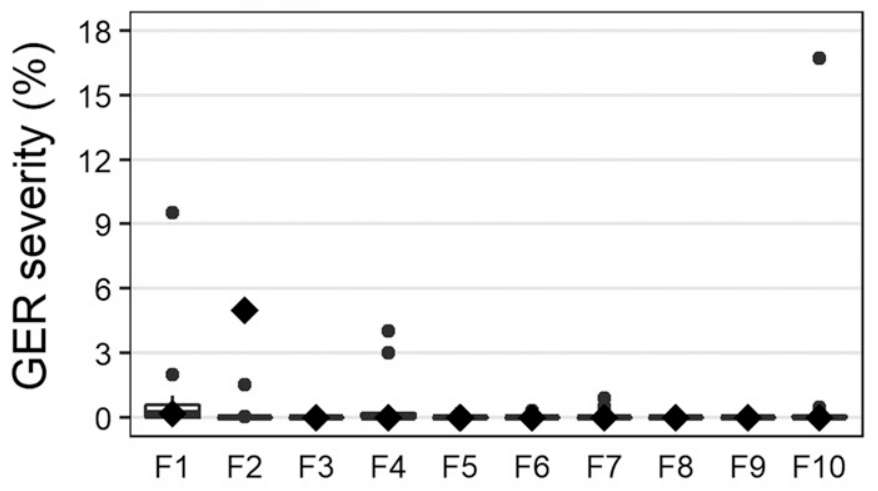

E $\quad 2018$

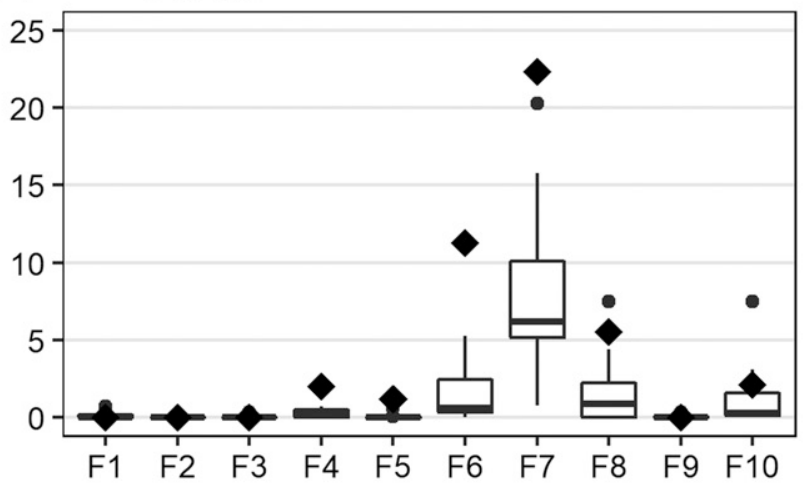

B 2016

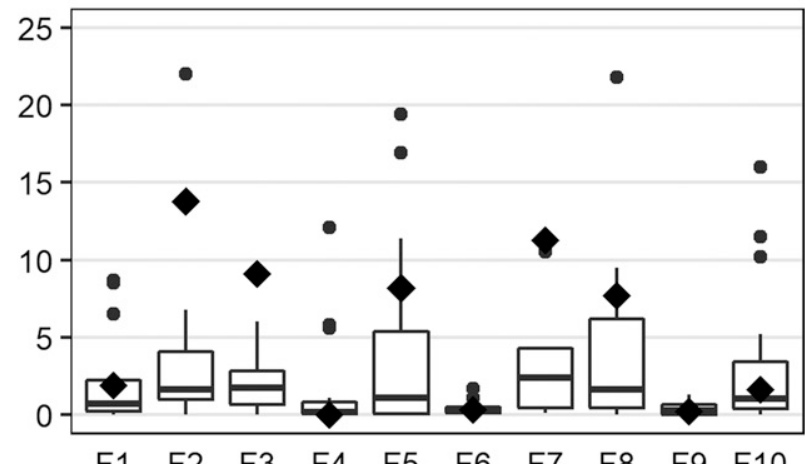

$\begin{array}{llllllllll}\text { F1 } & \text { F2 } & \text { F3 } & \text { F4 } & \text { F5 } & \text { F6 } & \text { F7 } & \text { F8 } & \text { F9 } & \text { F10 }\end{array}$

D 2017

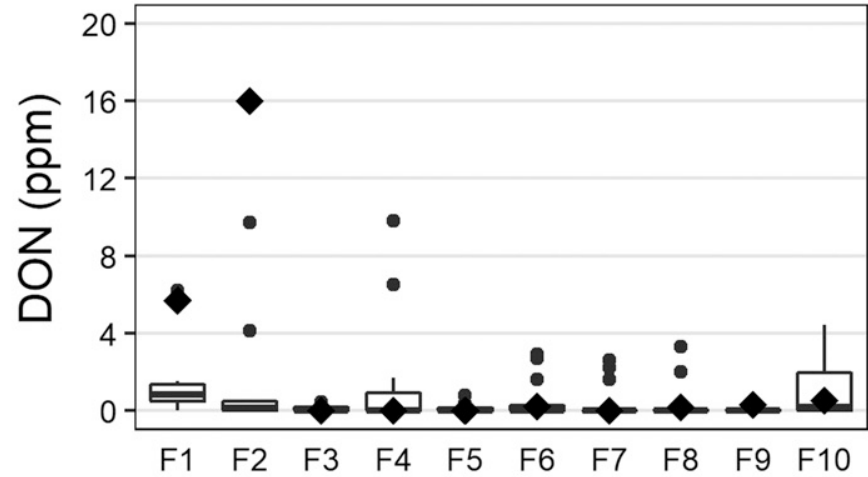

F 2018

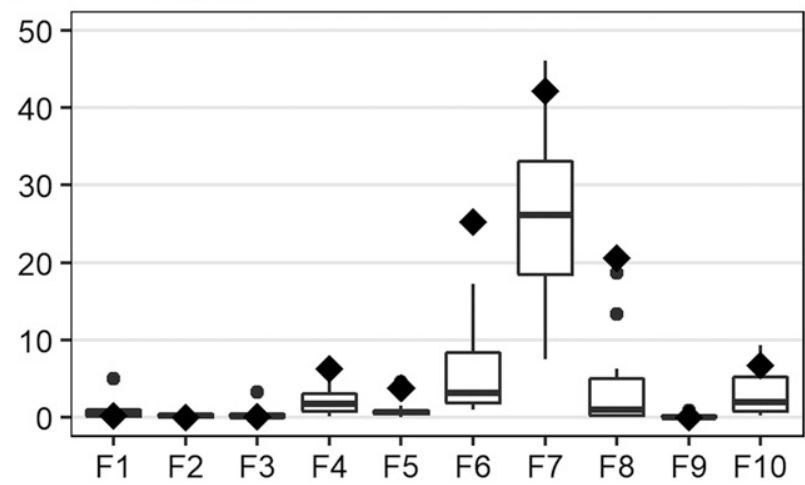

Fields

Fig. 2. Boxplots showing the distribution of $\mathbf{A}, \mathbf{C}$, and $\mathbf{E}$, mean Gibberella ear rot severity (GER; proportion of symptomatic ear area) and B, D, and $\mathbf{F}$, deoxynivalenol (DON) contamination of harvested grain at 10 field locations in 2016 (A and B), 2017 (C and D), and 2018 ( $E$ and F). Diamonds represent GER severity or DON contamination values for the reference susceptible hybrid. For each field, severity values are the means of 5 to 10 naturally infected ears for each of 15 to 16 hybrids. DON values are estimates for each hybrid from a composite sample of grain from the 5 to 10 ears. No symptoms of GER or DON contamination were detected for the 2015 season so the data were not displayed in the plot. Two extreme DON values (56.7 ppm for field F7 in 2016 and 34.9 ppm for field F10 in 2017) are not displayed in the plots but these values were used to make the boxplots, estimate the summary statistics, and conduct other analyses. The top and bottom lines of each box represent the 75th and 25th percentile of the data, respectively, whereas the line inside each box represents the 50th (median) percentile. Vertical bars extending beyond the boxes represent 1.5 times the interquartile distance. Fields were located in Licking (F1), Fayette (F2), Clark (F3), Darke (F4), Van Wert (F5), Wood (F6), Wyandot (F7), Crawford (F8), Wayne (F9), and Mahoning (F10) counties, Ohio. 
all weather variables, window lengths, diurnal periods (daylong and nighttime periods), and starting dates relative to $\mathrm{R} 1$ ranged from -0.696 to 0.713 . Although multiple weather variables were analyzed, due to space limitation and to avoid redundancy, we subset 21 of the 43 variables that represent the wide range of variables used in this study, especially featuring variables that show moderate to high correlation, at least for some windows. Heat maps of these associations for each of the six tested window lengths-days relative to R1 combinations are shown in the Supplementary Fig. S6 for all 43 weather variables and daylong summarization. Only correlation coefficients for the largest (negative or positive) $r$ values and the corresponding global levels of significance $\left(P_{g}\right)$ based on the Simes method for the six window lengths and 21 variables (the Simes test is based on the set of correlations, not specifically on the largest one) are shown in Table 2.

The magnitude, direction, and significance of the largest correlations varied with weather variable and window length (Table 2). Across the six window lengths, 11 weather variables had $r$ ranging from positive to negative across the different window lengths. The magnitude and sign (direction) of $r$ can change from positive to negative (or vice versa) for any fixed-length window, depending on the window position relative to R1 (Figs. 4 and 5). Therefore, the $r$ values in Table 2 are reported to show the highest correlations achieved for the different weather variables, and not the overall direction (across all windows) in the relationship between DON and the weather variable. The magnitude of the difference between the highest positive and highest negative $r$ was as high as 1.39 (minimum daily $\mathrm{RH}$ [RH.min]: difference in largest $r$ between the 5- and 20-day window lengths) (Table 2). For some variables, all of the largest $r$ values across the six window lengths were negative (R.S, total daily precipitation; RH.max, maximum daily RH; and T.L15, number of hours per day with $\mathrm{T}$ below $15^{\circ} \mathrm{C}$ ) or positive (mean, minimum, and maximum daily T [T.A, T.min, and T.max]; number of hour per day with $\mathrm{T} \geq$ $30^{\circ} \mathrm{C}$ [T.G30]; number of hours per day with $\mathrm{T}$ between 15 and $30^{\circ} \mathrm{C}$ and $\mathrm{RH} \geq 90 \%$ [TRH.15T30nRH90]; GDD, and VPD) (Table 2). In some cases, the largest $r$ values at a given window length for closely related variables such as TRH.15T30nRH80 (-0.645) and TRH.15T30nRH90 (0.634) at the 5-day window length were of similar magnitudes but of opposite directions. This was because the $r$ values were for different window start times (i.e., windows at different positions relative to R1; one before and the other after, for instance). Window positions are not shown in Table 2.

In general, T-, R-, and RH-related variables were significantly $\left(P_{g}<0.05\right)$ associated with DON contamination for most window lengths, except for RH.max, for which $P_{g}$ was $<0.05$ only for the 5-day window length. Variables such as TRH.15T30nRH80 (number of hours per day with $\mathrm{T}$ between 15 and $30^{\circ} \mathrm{C}$ and $\mathrm{RH} \geq 80 \%$ ) and TRH.15T30nRH90 and VPD that combined T and RH were highly significant for all window lengths, whereas variables derived from WE (daily mean WE [WE.A], number of hours with $\mathrm{WE} \geq 80 \%$ [WE.WE80] and $\geq 90 \%$ [WE.WE90]) were generally not statistically significant $\left(P_{g}>0.05\right)$. The exception was for WE.A, for which $r$ was significant $\left(P_{g}<0.05\right)$ for the 5-, 10-, and 15-day window lengths and marginally significant $\left(P_{g}<0.08\right)$ for the 20- and 25-day window lengths (Table 2). The $r$ coefficient was statistically significant for all but 3 (WE.WE80, WE.WE90, and RH.max) of the 21 weather variables considered in Table 2 for the 15-day window length, for 17 of the 21 variables for the 10- and 20-day window lengths, and for 16 variables for the 5-, 25-, and 30-day window lengths.

For mean daily T (T.A) and mean RH (RH.A) for two different time windows, trends in $r$ across the 91-day time frame were comparable for weather variables based on daylong and nighttime-only periods (Fig. 4A and B). In general, the association of weather variables with DON were either about the same or weaker when based on nighttime conditions rather than based on daylong conditions for the different weather variables analyzed (unpublished). Remaining results are thus based just on daylong conditions. Similarities in the $r$ profiles between window lengths over the 91-day time frame for two different weather variables are also apparent (Fig. 4), with greater smoothness (less jagged lines) in the associations with DON contamination for longer (15 to 30 days) than for shorter (5 and 10 days) window lengths (Fig. 4C and D). The results for RH.A (Fig. 4D) clearly show the changing sign of the maximum $r$ at different window lengths for this weather variable (Table 2). The temporal pattern in correlations was an increase in $r$ from negative to positive numbers with later windows for all window lengths. With the 5-day window, the largest $r$ was negative for an early window, then increased to positive values (although the positive values were never quite as large as the large early negative value for this window length). For longer-length windows (e.g., 15 days), the early negative $r$ values were not as extreme, and the positive $r$ values for later windows were the largest across the different window start times. The same general pattern (smoothness increasing with longer window lengths) was found for other weather variables (Supplementary Fig. S6). Therefore, the remaining results focus on one window length (15 days) based on the 21 daylong weather variables.

In general, as shown for RH.A (Fig. 4D), moisture-related weather summaries showed negative correlations with DON contamination before R1, followed by positive correlations after R1 (Fig. 5A to $\mathrm{K})$. For windows starting before R1, $r$ values were negative and within a similar range $(-0.288$ to -0.622 , median $=-0.477)$ for $\mathrm{R}-$ and RH-related variables (Fig. 5A to $\mathrm{H}$ ). In many cases, the weakest correlations of DON with moisture variables were observed for windows starting within the first 13 days after R1 ( $r$ median $=0.081)$, and the strongest correlations for those windows started between 15 and 20 days after $\mathrm{R} 1(r$ median $=0.417)$. For this latter group of window start times (15 to 20 days after R1), mean RH (RH.A), minimum

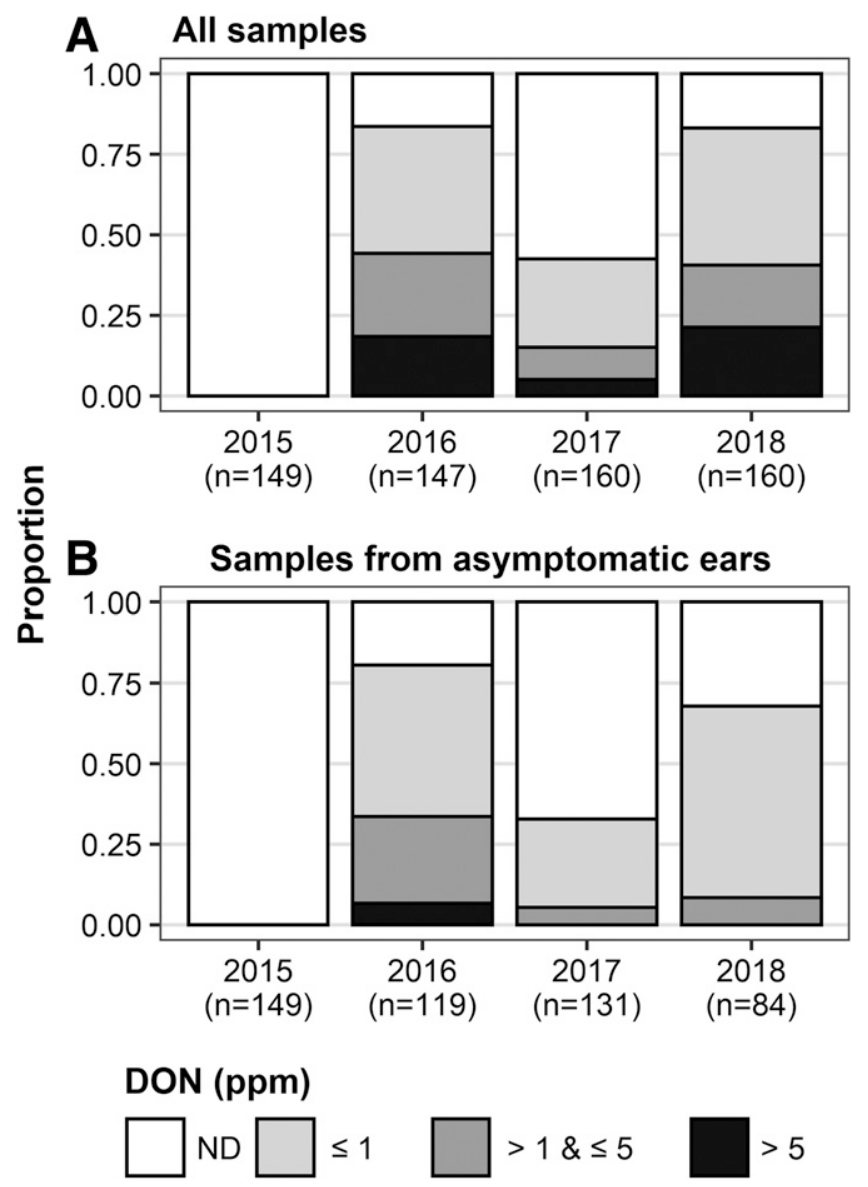

Fig. 3. Proportion of $\mathbf{A}$, all grain samples and $\mathbf{B}$, samples from ears without visual symptoms of Gibberella ear rot (GER; asymptomatic) with deoxynivalenol (DON) contamination below detectable limits (ND), less than $1 \mathrm{ppm}$, between 1 and 5 ppm, and above $5 \mathrm{ppm}$. Samples of grain from 5 to 10 ears were collected from each of 15 to 16 hybrids planted at 10 field locations in 2015, 2016, 2017, and 2018. DON was estimated separately for each hybrid-field-year combination from composite grain samples and then grouped based on whether or not the 5 to 10 ears from which the composite samples originated had a mean GER severity of zero (asymptomatic) or $\geq$ zero (all). Sample sizes are shown at the bottom of each box. 
RH (RH.min), and the number of hours with $\mathrm{RH} \geq 80 \%$ (RH.RH80) showed the strongest associations with DON of all the calculated moisture-only variables, with $r$ between 0.505 and 0.609 (Fig. 5D), 0.451 and 0.614 (Fig. 5E), and 0.469 and 0.571 (Fig. 5G), respectively. RH.A, RH.min, and RH.RH80 were also the moisture variables with the longest sequence of relatively large positive correlation coefficients of a similar magnitude ( 15 to 60 days after R1).

Among R-related variables (Fig. 5A to $\mathrm{C}$ ), the number of hours (R.AH; $r$ ranging from 0.390 to 0.492 ) and days (R.PA; $r$ from 0.324 to 0.509 ) with rain were more strongly associated with DON than total R (R.S; $r$ from 0.201 to 0.421 ) for 15 - and 30-day post$\mathrm{R} 1$ window start times. Among WE-related variables, mean WE showed stronger associations with DON (WE.A; $r$ from 0.292 to 0.415 ) than the number of hours with WE $\geq 80 \%$ (WE.WE80; $r$ from 0.221 to 0.367 ) or $\geq 90 \%$ (WE.WE90; $r$ from 0.219 to 0.356 ) for 14 and 20-day post-R1 window start times (Fig. 5I to K).

Like moisture variables, correlations between DON contamination and T-related variables also varied among window start times but, in general, warmer conditions were positively correlated with DON contamination, whereas cooler $\mathrm{T}$ was negatively correlated (Fig. $5 \mathrm{~L}$ to Q). For two of the six tested T-only variables (T.A and T.min; daily mean and minimum), $r$ values were positive across the entire time frame (Fig. 5L and M). For windows starting before $\mathrm{R} 1$, correlation coefficients were relatively large, positive, and highest among the T variables for T.A ( $r$ ranging from 0.247 to 0.598 , median $=0.474$ ), T.max (daily maximum; $r$ from 0.241 to 0.623 , median $=$ 0.512 ), and T.G30 (hours per day with $\mathrm{T} \geq 30^{\circ} \mathrm{C} ; r$ from 0.324 to 0.641 , median $=0.514)($ Fig. $5 \mathrm{~L}, \mathrm{~N}$, and P). Pre-R1 correlation trends were the opposite for T.15T30 (hours per day with T between 15 and $30^{\circ} \mathrm{C}$ ), with $r$ values being negative for all window start times, ranging from -0.577 to -0.136 (median $=-0.396$ ) (Fig. 5Q). For windows starting after $\mathrm{R} 1$, the highest positive correlations among $\mathrm{T}$ variables were observed for T.min between 13 to 17 days, with $r$ ranging from 0.498 to 0.573 (median $=0.547)$, and between 31 and 35 days for T.A, with $r$ ranging from 0.491 to 0.555 (median = 0.545 ). Correlation coefficients for GDD were mostly positive across the time frame (Fig. 5R) and very comparable with those estimated for T.A (Fig. 5L), whereas coefficients for the number of hours per day with $\mathrm{T}<15^{\circ} \mathrm{C}$ (T.L15) (Fig. 5O) were negative or close to zero across the entire time frame. The largest negative $r$ values for T.L15 occurred for start times between 14 to 18 days after R1 ( -0.513 to -0.479 , median $=-0.491$ ).

Variables consisting of combinations of $\mathrm{T}$ and RH were among the most strongly correlated with DON contamination both before and after $\mathrm{R} 1$. The number of hours per day with $\mathrm{T}$ between 15 and $30^{\circ} \mathrm{C}$ and $\mathrm{RH} \geq 80 \%$ (TRH.15T30nRH80) or $\geq 90 \%$ (TRH.15T30nRH90) had the strongest negative correlations for windows starting between 7 and 12 days before $\mathrm{R} 1$, with $r$ ranging from -0.614 to -0.506 and -0.494 to -0.433 , respectively (Fig. $5 \mathrm{~S}$ and T). The highest positive correlations for these variables occurred for windows starting between 14 and 19 days after R1, with $r$ between 0.563 and 0.679 for TRH.15T30nRH80 (Fig. 5R) and between 0.586 and 0.713 for TRH.15T30nRH90 (Fig. 5S). The highest correlations with DON contamination (in absolute value) for T-RH combination variables were numerically greater than the highest correlations for T- or RH-only-based variables. Trends in the correlations between VPD (Fig. 5U), a variable estimated from $\mathrm{T}$ and $\mathrm{RH}$, and DON contamination were opposite to those observed for TRH.15T30nRH80 and TRH.15T30nRH90 across the time frame, with the highest positive $r$ values before R1 ( 0.402 to 0.655 , median $=0.582$ ), particularly for windows starting between 7 and 16 days before the reference growth stage. The latter result was expected because of the negative relationship between VPD and RH.

\section{Discussion}

Moderate to high levels of GER severity and DON contamination of grain were detected on multiple hybrids at 10 locations in 3 of the 4

Table 2. Largest Spearman rank correlation coefficients $(r)$ and adjusted global significance levels $\left(P_{g}\right)$ based on the Simes method for associations between deoxynivalenol contamination and each of 21 selected weather variables for six window lengths

\begin{tabular}{|c|c|c|c|c|c|c|c|c|c|c|c|c|}
\hline \multirow[b]{3}{*}{ Variable $^{\mathbf{a}}$} & \multicolumn{12}{|c|}{ Window length (days) ${ }^{b}$} \\
\hline & \multicolumn{2}{|c|}{5} & \multicolumn{2}{|c|}{10} & \multicolumn{2}{|c|}{15} & \multicolumn{2}{|c|}{20} & \multicolumn{2}{|c|}{25} & \multicolumn{2}{|c|}{30} \\
\hline & $r$ & $P_{g}$ & $r$ & $P_{g}$ & $r$ & $P_{g}$ & $r$ & $P_{g}$ & $r$ & $P_{g}$ & $r$ & $\boldsymbol{P}_{g}$ \\
\hline R.AH & -0.505 & 0.054 & -0.528 & 0.014 & -0.561 & 0.006 & 0.569 & 0.003 & 0.580 & 0.002 & 0.592 & $<0.001$ \\
\hline R.PA & -0.531 & 0.026 & -0.524 & 0.025 & -0.622 & $<0.001$ & -0.609 & 0.002 & 0.583 & 0.004 & -0.533 & 0.005 \\
\hline R.S & -0.477 & 0.128 & -0.538 & 0.022 & -0.551 & 0.011 & -0.492 & 0.035 & -0.453 & 0.064 & -0.447 & 0.090 \\
\hline RH.A & -0.659 & $<0.001$ & -0.609 & 0.001 & 0.609 & $<0.001$ & 0.670 & $<0.001$ & 0.643 & $<0.001$ & 0.659 & $<0.001$ \\
\hline RH.min & -0.696 & $<0.001$ & -0.625 & $<0.001$ & 0.614 & $<0.001$ & 0.691 & $<0.001$ & 0.636 & $<0.001$ & 0.656 & $<0.001$ \\
\hline RH.max & -0.554 & 0.011 & -0.450 & 0.099 & -0.423 & 0.149 & -0.390 & 0.161 & -0.408 & 0.315 & -0.372 & 0.665 \\
\hline RH.RH80 & -0.688 & $<0.001$ & -0.650 & $<0.001$ & 0.632 & $<0.001$ & 0.658 & $<0.001$ & 0.647 & $<0.001$ & 0.648 & $<0.001$ \\
\hline RH.RH90 & -0.627 & $<0.001$ & -0.566 & 0.006 & -0.550 & 0.008 & 0.545 & 0.006 & 0.532 & 0.007 & 0.549 & 0.006 \\
\hline WE.A & -0.586 & 0.006 & -0.528 & 0.013 & 0.499 & 0.042 & 0.475 & 0.065 & 0.476 & 0.072 & 0.462 & 0.093 \\
\hline WE.WE80 & -0.425 & 0.292 & -0.319 & 0.521 & 0.367 & 0.590 & 0.279 & 0.618 & -0.252 & 0.620 & -0.252 & 0.660 \\
\hline WE.WE90 & -0.428 & 0.292 & -0.317 & 0.521 & 0.356 & 0.590 & 0.286 & 0.618 & -0.241 & 0.620 & 0.242 & 0.660 \\
\hline T.A & 0.524 & 0.011 & 0.560 & 0.005 & 0.598 & 0.002 & 0.578 & 0.003 & 0.589 & 0.002 & 0.567 & 0.003 \\
\hline T.min & 0.593 & 0.004 & 0.585 & 0.004 & 0.573 & 0.005 & 0.524 & 0.008 & 0.502 & 0.008 & 0.512 & 0.006 \\
\hline T.max & 0.568 & 0.004 & 0.583 & 0.002 & 0.623 & $<0.001$ & 0.609 & 0.002 & 0.589 & 0.003 & 0.578 & 0.003 \\
\hline T.L15 & -0.528 & 0.023 & -0.541 & 0.017 & -0.513 & 0.017 & -0.503 & 0.019 & -0.480 & 0.022 & -0.479 & 0.023 \\
\hline T.G30 & 0.589 & 0.003 & 0.633 & $<0.001$ & 0.641 & $<0.001$ & 0.639 & $<0.001$ & 0.578 & 0.002 & 0.594 & 0.002 \\
\hline T.15T30 & 0.409 & 0.126 & -0.488 & 0.086 & -0.577 & 0.006 & -0.571 & 0.008 & -0.482 & 0.040 & -0.468 & 0.047 \\
\hline GDD & 0.528 & 0.021 & 0.511 & 0.027 & 0.546 & 0.007 & 0.526 & 0.009 & 0.545 & 0.005 & 0.528 & 0.009 \\
\hline TRH.15T30nRH80 & -0.645 & $<0.001$ & 0.625 & $<0.001$ & 0.679 & $<0.001$ & 0.661 & $<0.001$ & 0.640 & $<0.001$ & 0.634 & $<0.001$ \\
\hline TRH.15T30nRH90 & 0.634 & $<0.001$ & 0.636 & $<0.001$ & 0.713 & $<0.001$ & 0.688 & $<0.001$ & 0.634 & $<0.001$ & 0.641 & $<0.001$ \\
\hline VPD & 0.694 & $<0.001$ & 0.634 & $<0.001$ & 0.655 & $<0.001$ & 0.648 & $<0.001$ & 0.626 & $<0.001$ & 0.614 & $<0.001$ \\
\hline
\end{tabular}

${ }^{\mathrm{a}} \mathrm{R}=$ rainfall $(\mathrm{mm}), \mathrm{RH}=$ relative humidity $(\%), \mathrm{T}=$ temperature $\left({ }^{\circ} \mathrm{C}\right)$, and $\mathrm{WE}=$ surface wetness $(\%)$. R.AH $=$ hours with R; R.PA $=$ days with R; R.S $=$ total precipitation; RH.A = mean RH; RH.min = minimum RH; RH.max = maximum RH; RH.RH $80=$ hours with RH $\geq 80 \%$; RH.RH90 = hours with RH $\geq 90 \%$; WE.A $=$ mean surface wetness; WE.WE80 = hours with $\mathrm{WE} \geq 80 \%$; WE.WE90 = hours with WE $\geq 90 \%$; T.A $=$ mean T; T.min $=\operatorname{minimum~T;~T.max~}=$ maximum T; T.L15 = hours with $\mathrm{T} \leq 15^{\circ} \mathrm{C} ; \mathrm{T} . \mathrm{G} 30=$ hours with $\mathrm{T} \geq 30^{\circ} \mathrm{C} ; \mathrm{T} .15 \mathrm{~T} 30=$ hours with $\mathrm{T}$ between 15 and $30^{\circ} \mathrm{C} ; \mathrm{GDD}=$ sum of growing degree days $\left({ }^{\circ} \mathrm{C}\right) ; \mathrm{TRH} .15 \mathrm{~T} 30 \mathrm{nRH} 80=$ hours with $\mathrm{T}$ between 15 and $30^{\circ} \mathrm{C}$ and $\mathrm{RH} \geq 80 \%$; TRH. $15 \mathrm{~T} 30 \mathrm{nRH} 90=$ hours with $\mathrm{T}$ between 15 and $30^{\circ} \mathrm{C}$ and $\mathrm{RH} \geq 90 \%$; and $\mathrm{VPD}=$ vapor pressure deficit $(\mathrm{kPa})$.

${ }^{\mathrm{b}}$ Largest Spearman $r$ was calculated from window-pane analyses for each variable and window length combination. Correlation values are an average of bootstrap with 1,000 samplings. Largest $r$ value is shown to indicate the highest degree of association found across the profile of windows of any given window length. $P_{g}=$ global level of significance adjusted based on the method proposed by Simes (1986) for multiple comparisons; values $P_{g} \leq 0.05$ are considered significant. Significance is based on the set of individual $P$ values (one for each correlation for each window for the profile over time), not based on the maximum $r$ shown here. 
years of this study, suggesting that this disease and its associated toxins may be more frequently occurring in Ohio than previously thought by growers and crop advisors. Most previous peer-reviewed publications on natural contamination of maize with mycotoxins in the Midwest region came from analyses of grain samples and DDGS from ethanol plants (Khatibi et al. 2014; Zhang and Caupert 2012; Zhang et al. 2009). Findings from one such study (Khatibi et al. 2014) alluded to the importance of DON in Ohio; 25\% of the 141 DDGS samples collected from 78 ethanol plants in 2011 in 12 U.S. states had mean DON levels between 1 and 5 ppm, with samples from Ohio being the most contaminated. Biomin (Biomin America, Inc., Overland Park, KS, U.S.A.) also provides annual estimates of DON (and other mycotoxin) contamination of grain in several regions and countries. However, although extremely informative, these types of surveys are not designed to address questions regarding seasonal or farmto-farm variations, or environmental effects in DON contamination. Ethanol plant surveys are more often conducted when there are socalled GER outbreaks.

Though prevalent in 2016, 2017, and 2018, GER severity and DON contamination varied among seasons, locations within seasons, and hybrids. This partly reflects the influence of spatiotemporal variations in environmental conditions and host resistance on disease development and DON contamination, and helps to explain, at least in part, the sporadic nature of high levels of the disease and mycotoxin. Cool, wet conditions (Munkvold 2003; Munkvold and White 2016; Sutton 1982), particularly moisture during and shortly after R1, rainfall during grain fill and harvest (Munkvold 2003; Sutton 1982), and temperatures ranging from below $22^{\circ} \mathrm{C}$ (Sutton 1982) to $28^{\circ} \mathrm{C}$ (Reid et al. 1999) have been reported as being most favorable for GER development. Indeed, 2016 and 2018, seasons with the highest levels of GER, experienced more frequent and greater amounts of rainfall during the first month after R1 than in 2015 and 2017.
Given the role of DON as a virulence factor in GER development (Harris et al. 1999), conditions favorable for the development of visual symptoms are often thought to also favor DON accumulation. However, observations made here and in studies with other related pathosystems (Chu and Li 1994; Clements et al. 2003; Cowger and Arrellano 2010; Paul et al. 2006; Xu et al. 2014) suggest that this is not necessarily the case. Multiple grain samples from healthylooking ears had detectable levels of DON. Although the DON content of asymptomatic grain is commonly reported to be lower than that of symptomatic grain (Reid et al. 1996), our results showed that contamination of asymptomatic grain could exceed $5 \mathrm{ppm}$, a regulatory advisory limit established by the U.S. Food and Drug Administration (Khatibi et al. 2014). This is consistent with previous reports of DON contamination in healthy-looking wheat grain harvested from spikes without visual symptoms of FHB, a related disease that is caused by the same pathogen as GER (Cowger and Arrellano 2010; Hallen-Adams et al. 2011; Paul et al. 2006; Peiris et al. 2011).

Other than the physical environment and hybrid resistance, differences in pathogen populations could have also contributed to variations in GER and DON among location-years. Chemotype is one such population-specific trait that has been reported to affect disease and toxin levels in other pathosystems (Foroud et al. 2012; Puri and Zhong 2010; Valverde-Bogantes et al. 2019; Ward et al. 2008). Here, we indirectly evaluated the chemotype of $F$. graminearum in Ohio's maize fields by analyzing the type B trichothecene profile of 320 grain samples from 16 hybrids at 10 locations over two growing seasons. The presence of $15 \mathrm{ADON}, 3 \mathrm{ADON}$, or NIV in samples is often taken as evidence of the specific chemotypes of the pathogen that produce these toxins in a population (Bissonnette et al. 2018; Tittlemier et al. 2020; Vogelgsang et al. 2017). Only 15ADON and DON were detected in our samples, suggesting that the $F$. graminearum population that infected maize in our trials was primarily of the $15 \mathrm{ADON}$ chemotype.

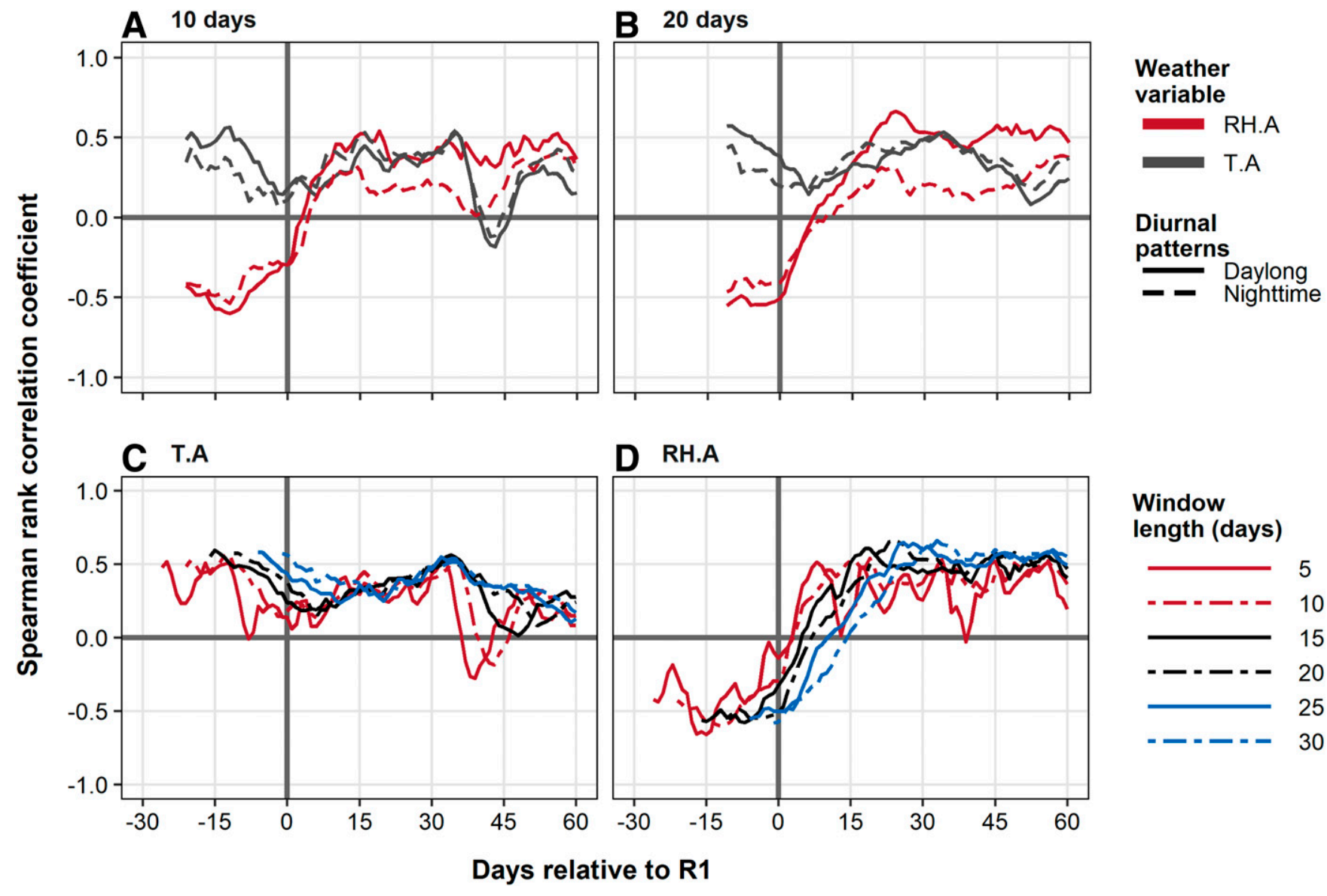

Fig. 4. Spearman rank correlation coefficients for associations between deoxynivalenol (DON) contamination and mean temperature $\left(T . A,{ }^{\circ} \mathrm{C}\right)$ and DON and mean relative humidity (RH.A, \%) for daylong (24-h) and nighttime (overnight [2000 to $0800 \mathrm{~h}]$ ) periods for A, 10-day window lengths and B, 20-day window lengths; and between C, DON and T.A and D, DON and RH.A for daylong periods for six different window lengths $(5,10,15,20,25$, and 30 days). Day 0 represents the R1 (silking) reference growth stage. 
Although our results are not based on direct molecular characterization of the isolates, they are consistent with findings from similar studies of wheat and maize grain samples from Ohio and surrounding regions (Bec et al. 2015; Gale et al. 2007). For instance, Khatibi et al. (2014) reported that $15 \mathrm{ADON}$ was the only type $\mathrm{B}$ trichothecene detected in the 141 DDGS samples they collected from ethanol plants in 12 U.S. states, including Ohio, Michigan, and Indiana. Similarly, Burlakoti et al. (2017) reported that $96 \%(n=452)$ of the F. graminearum isolates from maize grain samples collected in Ontario, Canada from 2010 to 2012 were of the 15ADON-producing chemotype.
A R.AH

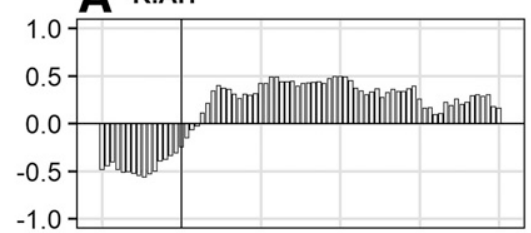

D RH.A
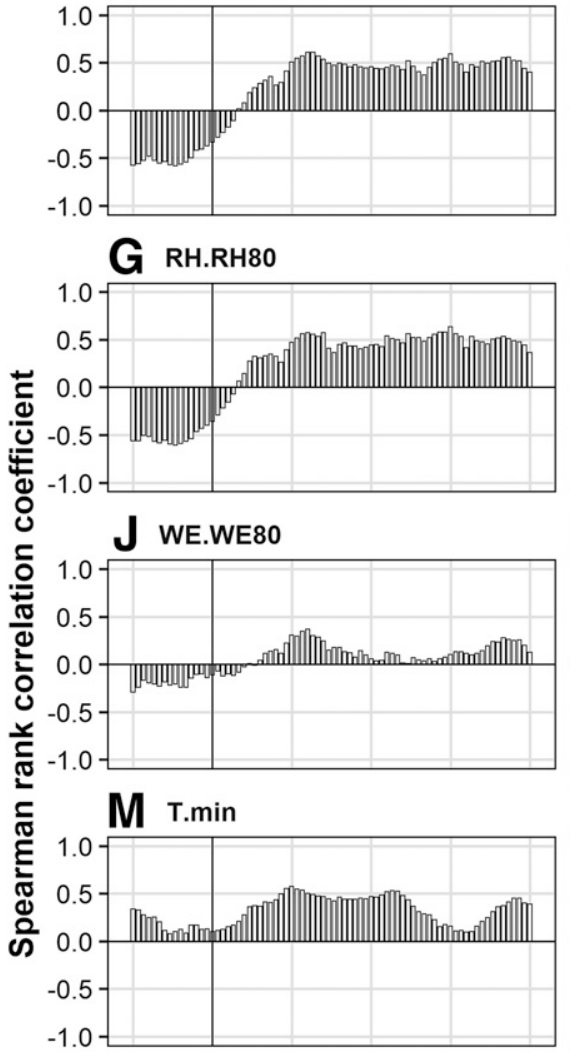

$$
\text { P T.G30 }
$$
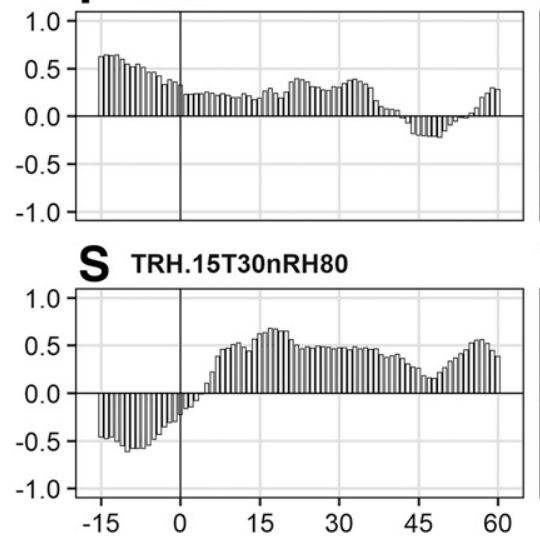

B R.PA

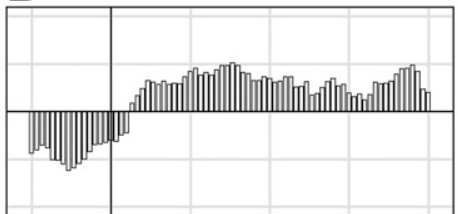

E RH.min

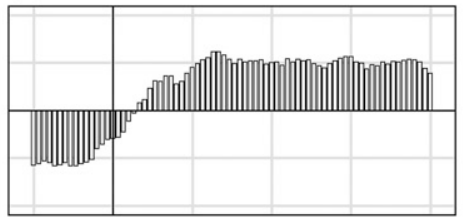

H RH.RH90

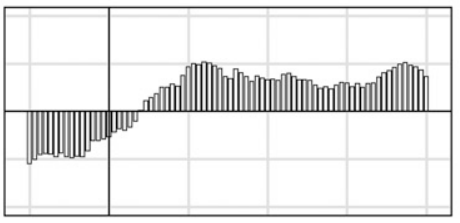

K WE.WE90

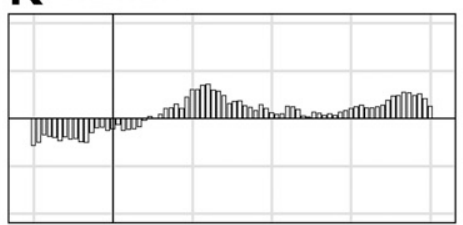

N T.max

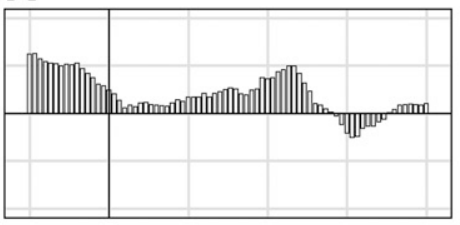

Q T.15T30
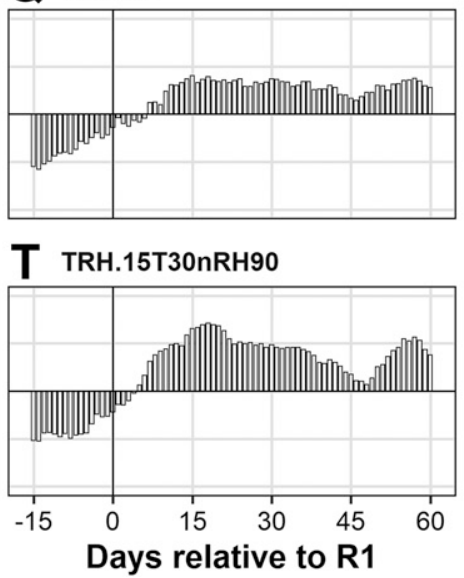

C R.S

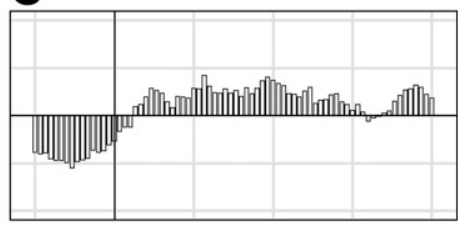

\section{F RH.max}

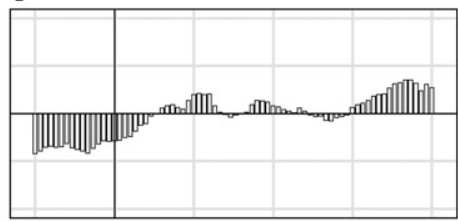

| WE.A

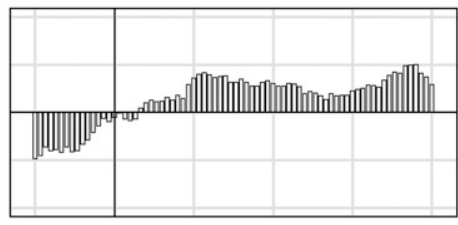

L T.A

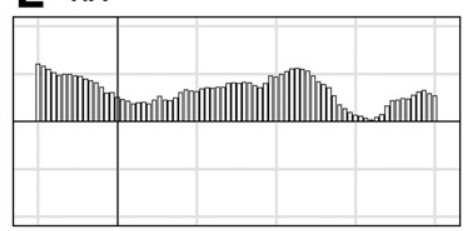

O T.L15

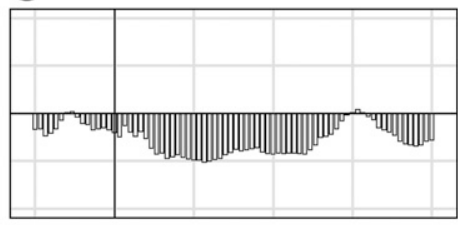

R GDD
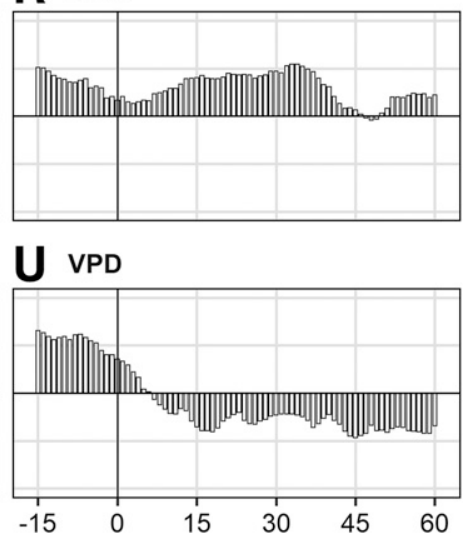

Fig. 5. Spearman rank correlation coefficients for associations between deoxynivalenol (DON) contamination and 21 selected weather variables for daylong periods and 15 -day window lengths. Coefficients are shown for $\mathbf{A}$ to $\mathbf{C}$, rainfall $(\mathrm{R})$-related variables (R.AH = hours with rain, $R . P A=R(Y e s / N o)$, and $R . S=$ total precipitation); $\mathbf{D}$ to $H$, relative humidity $(\mathrm{RH})$-only variables (RH.A, RH.min, and RH.max = mean, minimum, and maximum $\mathrm{RH}$, respectively, and $\mathrm{RH} . \mathrm{RH} 80$ and $\mathrm{RH} . \mathrm{RH} 90=$ hours with $\mathrm{RH} 80 \geq$ and $\geq 90 \%$, respectively); I to $\mathrm{K}$, surface wetness (WE)-related variables (WE.A = mean WE, WE.WE80 = hours with WE $\geq 80 \%$; WE.WE90 = hours with WE $\geq 90 \%$ ); $\mathrm{L}$ to $\mathrm{R}$, temperature (T)-only variables (T.A, T.min, and T.max = mean, minimum and maximum T, respectively, T.L15 = hours with $\mathrm{T} \leq 15^{\circ} \mathrm{C}, \mathrm{T} . \mathrm{G} 30=$ hours with $\mathrm{T} \geq 30^{\circ} \mathrm{C}, \mathrm{T} .15 \mathrm{~T} 30=$ hours with $\mathrm{T}$ between 15 and $30^{\circ} \mathrm{C}$, and $\mathrm{GDD}=$ growing degree days); and $\mathbf{S}$ to $\mathrm{U}, \mathrm{T}-\mathrm{RH}$ combination variables (TRH. $15 \mathrm{~T} 30 \mathrm{nRH} 80=$ hours with $\mathrm{T}$ between 15 and $30^{\circ} \mathrm{C}$ and $\mathrm{RH} \geq 80 \%$, TRH. $15 \mathrm{~T} 30 \mathrm{nRH} 90=$ hours with $\mathrm{T}$ between 15 and $30^{\circ} \mathrm{C}$ and $\mathrm{RH} \geq 90 \%$, and VPD = vapor pressure deficit). Each vertical bar represents the coefficient for a 15-day summary for a specific window start time. Day 0 represents the R1 (silking) reference growth stage, with negative values before R1 and positive values after R1. 
A more comprehensive survey of fungal isolates would be needed before we can say with a greater degree of confidence that $3 \mathrm{ADON}-$ producing and NIV-producing chemotypes are not present in Ohio's maize fields. However, given that the 15ADON-producing chemotype has historically been the predominant $F$. graminearum population in Ohio and other parts of the Midwest (Gale et al. 2007) and MidAtlantic (Schmale et al. 2011), our results could be interpreted to mean that there is no evidence in our data for a chemotype shift in the maizeinfecting population of the pathogen in Ohio. This is contrary to what has been reported to be the case with wheat- and barley-infecting populations in some states (Burlakoti et al. 2011; Puri and Zhong 2010; Ward et al. 2008). This is important, because such a shift has been hypothesized as a possible reason for recent increases in GER severity and DON contamination in the region. In some studies, 3ADONproducing chemotypes were reported to be more aggressive than 15ADON-producing chemotypes, causing higher levels of disease and producing more DON (Foroud et al. 2012; Puri and Zhong 2010; Valverde-Bogantes et al. 2019; Ward et al. 2008).

An intent in this investigation was to formally quantify weather associations with DON at a finer scale than overall seasonal or regional summaries such as "warm seasons", "wet year", "cool-wet region", and so forth. Those types of general qualitative associations do not capture field-to-field variations in DON and are not ideal for objectives such as the development of risk assessment tools to help guide management and grain handling and marketing decisions. Here, we utilized the window-pane algorithm (Coakley et al. 1985; Kriss et al. 2010, 2012) to generate finer weather summaries for specific periods and number of consecutive days (window start times and lengths) relative to $\mathrm{R} 1$, the growth stage of greatest host susceptibility to infect (Munkvold 2003; Sutton 1982). The window-pane algorithm allowed us to consider, in an exploratory data-mining sense, a large number of weather summaries representing different combinations of weather variables-window start time-window length and estimate their individual correlations with DON.

Of the six window lengths evaluated, short windows gave more erratic behavior of the Spearman rank correlation $(r)$ over time compared with longer windows, with increasing smoothness to the temporal pattern of $r$ with increasing window duration, especially for 15-day or longer windows. This is commonly found with other window-pane analyses (Kriss et al. 2010; Xu et al. 2019). Correlation coefficients for shorter windows were more variable, likely because weather variables summarized over 5- or 10-day windows tended to be more sensitive to single-day weather extremes, which may be out of proportion to the actual effect of the weather variable on DON. For instance, using a 5-day window and mean daily temperature as an example, one extremely warm day at the start of the window (20\% of the data in that window) could result in a substantial increase in the 5-day mean temperature, increasing or decreasing its correlation with DON. However, that warm day quickly drops out of the window after five timesteps, causing the 5-day mean temperature to drop, again changing its correlation with DON. On the other hand, with a 30-day window, a single very warm day entering the window would have less of an effect on the 30-day mean, causing the correlation (strong or weak) to remain fairly constant after multiple timesteps, unless a stretch of several unseasonably warm or cold days enters the window. However, there is a balance that is attempted in considering different window lengths. Very short windows may be overly sensitive to extremes (outliers) but long windows may aggregate weather information for too long of a time, masking actual (true) effects of the weather variable over a shorter time (say, if conditions during a short window are truly determining the biological response). Although not considered here, very long windows (e.g., >30 days) may cancel out the information found in shorter windows by merging time periods, only some of which are actually affecting the variable of interest (Kriss et al. 2010; Xu et al. 2019). An important concept behind window-pane analysis is to find the window length that provides the highest but not erratic correlations with DON (or any response variable) without averaging out important effects (Coakley et al. 1988; Kriss et al. 2010, 2012). A similar goal is behind functional data analysis (Shah et al. 2019b).
The 15-day time window was found to be a reasonable time duration for representing the association between DON and the weather variables in our investigation. There was a tendency for the largest correlations to be found with this window length compared with the others, and there were more significant correlations based on the Simes test compared with other windows. The 5-day window also had high correlations but a more erratic pattern over time, making interpretation more difficult. Short 5- and 10-day windows were likely too short to include the optimum duration of weather required to promote DON production (at least for some variables), whereas the 25 and 30-day-long windows likely had too many days of less favorable weather that diluted somewhat the effects of the days or stretches of more favorable weather. Interestingly, 14- and 15-day windows were also among the best for summarizing some weather predictors of FHB risk (Shah et al. 2013, 2014; Xu et al. 2013).

For a given window length (15-day in this case), there was no advantage to dividing the daylong (24-h) weather variables into shorter 12-h, nighttime ( 800 P.M. to 800 A.M.) periods. This is contrary to results from some other studies, in which nighttime summaries were more strongly correlated with and better predictors of disease intensity than daylong representations for some variables (Paul and Munkvold 2005; Shah et al. 2013, 2014). For instance, Shah et al. $(2013,2014)$ found nighttime summaries of several variables (particularly those related to $\mathrm{RH}$ and $\mathrm{RH}-\mathrm{T}$ combinations) to be good predictors of FHB index (field severity = average area of the wheat spikes with symptoms). One might have expected similar results or trends, given that FHB and GER are caused by the same pathogen. However, differences could be due to the fact that Shah et al. $(2013,2014)$ were investigating associations between weather variables and FHB severity whereas, here, we investigated weather associations with DON contamination, a response that is not always proportional to visual symptoms for reasons discussed elsewhere (Cowger et al. 2009; Culler et al. 2007; Hart 1984; Moraes et al. 2018; Paul et al. 2006; Xu et al. 2014).

For the 15-day window length (or any other tested window length), the association between weather variables and DON varied with the position of the window relative to R1. For most of the 21 variables considered in detail, windows straddling $\mathrm{R} 1$ had some of the weakest correlations with DON contamination. This may seem surprising, given the importance of the R1 growth stage for the establishment of natural infection (Miller 1994; Munkvold 2003; Sutton 1982). However, the weak correlations between DON and weather summaries spanning the R1 window could be due to the fact that $\mathrm{DON}$ is not required for infection. This has been demonstrated in several virulence studies in both wheat and maize using isolates of the fungus that were engineered not to produce trichothecenes (Bai et al. 2002; Desjardins 1996; Harris et al. 1999; Proctor 1995). Based on results from these same studies, DON was needed for spread of the fungus or infection within spikes or ears. This postinfection process for which DON is required likely begins toward the end of the R1 window and continues as more kernels are colonized. Indeed, our results showed that several of the variables investigated had their strongest positive correlations with DON for windows extending from a few days to about 14 to 21 days after R1.

Several variables, particularly those related to temperature and moisture, also had some of their strongest (positive or negative) correlations with DON for windows extending from about 7 to 30 days before R1. Significant correlations between DON and pre-R1 weather could be attributed to complex interactions among several factors, including associations among weather variables and their influence on crop development and inoculum production and dissemination (the latter leading to infection and later DON production) (Munkvold 2003; Sutton 1982). Silk emergence, viability, and susceptibility to infection are all very important for GER development (Miller et al. 2007; Reid et al. 1992; Thompson and Raizada 2018). Conditions before R1 could impact silk development and other physiological processes (Borrás and Vitantonio-Mazzini 2018) related to silk resistance to infection by $F$. graminearum (Reid et al. 1992).

All moisture-related variables showed a similar pattern, with negative correlations for windows positioned before R1 followed by 
positive associations for those positioned after R1. This trend partly corroborates the well-established consensus that GER is favored by high-moisture conditions (Miller 1994; Munkvold 2003; Munkvold and White 2016; Sutton 1982), particularly after R1. This could be attributed to the role of post-R1 moisture on fungus colonization and mycotoxin production (Manstretta et al. 2016; Munkvold 2003; Ramirez et al. 2006; Sutton 1982). The post-R1 moisture association with DON was most consistent for daily mean and minimum RH and hours with $\mathrm{RH} \geq 80 \%$, all of which had significant positive correlation coefficients for virtually all 15-day windows across the entire post-R1 period. However, for all tested moisture variables, windows extending from about 7 to 30 days before R1 had some of the highest negative correlations with DON. This suggested that relatively dry pre-R1 conditions were more favorable for DON contamination.

Although it is not clear why dry conditions before R1 would be conducive to DON contamination, we speculate (based on previous research) that this could be related to spore dissemination, particularly ascospore release. Studying the dissemination of spores of Gibberella zeae, the teleomorph and overwintering stage of $F$. graminearum, Paulitz (1996) reported that although R and high RH were required for perithecia and ascospore production and maturation, ascospore release was negatively affected by days with continuous $\mathrm{RH}>80 \%$ or $\mathrm{R}>5 \mathrm{~mm}$. The author concluded that dryness during the day followed by an increase in $\mathrm{RH}$ during the evening hours served as the stimulus for ascospore release from perithecia. Although we have no information on perithecia or ascospore release in our correlation study, any factor that reduces spore release could affect GER development and, consequently, DON accumulation. In addition, it is quite possible that what appears to be negative pre-R1 moisture associations with DON could, in fact, be the result of the well-known inverse relationship between atmospheric moisture and temperature (Stull 2011), with increasing pre-R1 temperature variables (coincident with moisture decrease) in our study being associated with increasing DON.

Warm-temperature variables also had positive associations with DON contamination during post-R1 periods. There have been several other reports of GER development under moderate to warm conditions; Miller (1994) associated ear colonization with rainfall and warm temperature during silking; Reid et al. (1999) found that the optimum temperature for $F$. graminearum growth on maize silks was between 26 to $28^{\circ} \mathrm{C}$; Sutton (1982) reported that temperatures from $<22$ to $24^{\circ} \mathrm{C}$ were associated with GER outbreaks; and, based on an 8-year study in Ontario, Canada, Hooker and Schaafsma (2005) found that a higher incidence of DON was observed in years with temperatures above normal around the R1 growth stage. These results are at odds with the common thinking that GER is a cooltemperature disease (Munkvold 2003; Munkvold and White 2016; Sutton 1982). However, it is worth mentioning that, in most observational studies or documented reports of the natural occurrence of GER, recorded or estimated temperatures were frequently accompanied by R or high RH (Miller 1994; Munkvold 2003; Munkvold and White 2016; Sutton 1982). The effects of combined T- and RHrelated variables on different crop development and infection cycle components described above would help to explain why combinations of $\mathrm{T}$ and $\mathrm{RH}$ variables such as the number of hours with $\mathrm{T}$ between 15 and $30^{\circ} \mathrm{C}$ with $\mathrm{RH} \geq 80$ or $\geq 90 \%$ had some of the strongest (positive or negative) correlations with DON contamination of all the tested weather variables.

The environment may have direct effects on DON production after or independent of GER development. Several of the studies on this subject were done under controlled conditions, often with the wheat-FHB-DON system, but may be representative of what could be occurring in the maize-GER-DON system. Based on designed wheat experiments, Hart (1984), Cowger et al. (2009), Culler et al. (2007), and Moraes et al. (2018) all reported changes in DON contamination of grain in response to late-season simulated rainfall or mist treatments (with relatively little change in disease severity). Similarly, positive associations between moisture and DON were reported in controlled-environment investigations of the effects of water activity $\left(a_{w}\right)$ on grain contamination with DON (Hope et al. 2005;
Llorens et al. 2004; Ramirez et al. 2006; Schmidt-Heydt et al. 2011). For instance, Ramirez et al. (2006) reported that the DON content of wheat grain increased under laboratory conditions as $a_{w}$ increased, and that DON was produced earlier at $25^{\circ} \mathrm{C}$ than at 5,15 , or $30^{\circ} \mathrm{C}$ but reached the highest levels at $30^{\circ} \mathrm{C}$.

In conclusion, GER and DON are important concerns for maize production in Ohio and surrounding states. Given that these problems may go undetected until harvest or grain processing, routine field scouting, ear inspection, harvested grain sampling, and DON testing are required to detect and quantify the disease or toxin, especially in years with conducive conditions for infection and DON accumulation. Through window-pane analysis, we identified and characterized some weather conditions associated with DON, showing that DON contamination was correlated with specific representations of warm $\mathrm{T}$, high $\mathrm{RH}$, and $\mathrm{R}$. We identified several 15-day summaries of moderate-to-warm $\mathrm{T}\left(15\right.$ to $\left.30^{\circ} \mathrm{C}\right)$ and high $\mathrm{RH}(>80 \%$ or $>90 \%)$ combinations, positioned between 1 and 21 days after R1 as having some of the strongest associations with DON, based on the magnitude and significance of estimated correlation coefficients. These variables would be excellent candidate predictors for the development of riskassessment models. However, several other combinations of window lengths, positions relative to $\mathrm{R} 1$, and weather variables with statistically significant but numerically lower coefficients could also be used to evaluate the risk of DON contamination. This allows for flexibility in terms of the combinations of factors that one could use in the future to develop DON prediction models. Although our findings were based on data from a single susceptible hybrid, preliminary analyses using six hybrids with different levels of resistance to GER showed that the trends were very consistent across resistance classes (F. Dalla Lana, unpublished). However, more studies with larger sample sizes conducted over multiple years and states will benefit ongoing efforts to better understand the biology and epidemiology of GER and DON in order to develop risk assessment tools.

\section{Acknowledgments}

We thank P. Thomison and R. Minyo for their help with the establishment and management of the Ohio Corn Performance Trials.

\section{Literature Cited}

Abendroth, L. J., Elmore, R. W., Boyer, M. J., and Marlay, S. K. 2011. Corn Growth and Development-PMR 1009. Iowa State University Extension, Ames, IA, U.S.A

Astoreca, A., Ortega, L., Fígoli, C., Cardós, M., Cavaglieri, L., Bosch, A., and Alconada, T. 2017. Analytical techniques for deoxynivalenol detection and quantification in wheat destined for the manufacture of commercial products. World Mycotoxin J. 10:111-120.

Bai, G. H., Desjardins, A. E., and Plattner, R. 2002. Deoxynivalenol-nonproducing Fusarium graminearum causes initial infection, but does not cause disease spread in wheat spikes. Mycopathologia 153:91-98.

Barker, D. J., Culman, S., Dorrance, A., Fulton, J., Haden, R., Lentz, E., Lindsey, A., Lindsey, L., Loux, M., McCoy, E., Michel, A., Noel, J., Paul, P. A., Sulc, R. M., Thomison, P., Tilmon, K., and Witter, J. 2017. Ohio Agronomy Guide, 15th ed. Ohio State University Extension, Columbus, OH, U.S.A

Bec, S., Ward, T., Farman, M., O'Donnell, K., Hershman, D., Van Sanford, D., and Vaillancourt, L. J. 2015. Characterization of Fusarium strains recovered from wheat with symptoms of head blight in Kentucky. Plant Dis. 99: 1622-1632.

Bissonnette, K. M., Kolb, F. L., Ames, K. A., and Bradley, C. A. 2018. Effect of wheat cultivar on the concentration of Fusarium mycotoxins in wheat stems. Plant Dis. 102:2539-2544.

Borrás, L., and Vitantonio-Mazzini, L. N. 2018. Maize reproductive development and kernel set under limited plant growth environments. J. Exp. Bot. 69: 3235-3243.

Bosen, J. F. 1958. An approximation formula to compute relative humidity from dry bulb and dew point temperatures. Mon. Weather Rev. 86:486.

Burlakoti, R. R., Neate, S. M., Adhikari, T. B., Gyawali, S., Salas, B., Steffenson, B. J., and Schwarz, P. B. 2011. Trichothecene profiling and population genetic analysis of Gibberella zeae from barley in North Dakota and Minnesota. Phytopathology 101:687-695.

Burlakoti, R. R., Tamburic-Ilincic, L., Limay-Rios, V., and Burlakoti, P. 2017 Comparative population structure and trichothecene mycotoxin profiling of Fusarium graminearum from corn and wheat in Ontario, Central Canada. Plant Pathol. 66:14-27.

Calvero, S. B., Jr., Coakley, S. M., and Teng, P. S. 2003. Development of empirical forecasting models for rice blast based on weather factors. Plant Pathol. 45 667-678. 
Canty, A. and Ripley, B. D. 2019. boot: Bootstrap R (S-plus) functions (version 1.3-23). https://rdrr.io/cran/boot/

Chu, F. S., and Li, G. Y. 1994. Simultaneous occurrence of fumonisin B1 and other mycotoxins in moldy corn collected from the People's Republic of China in regions with high incidences of esophageal cancer. Appl. Environ. Microbiol. 60:847-852.

Clements, M. J., Kleinschmidt, C. E., Maragos, C. M., Pataky, J. K., and White, D. G. 2003. Evaluation of inoculation techniques for Fusarium ear rot and fumonisin contamination of corn. Plant Dis. 87:147-153.

Coakley, S. M., Line, R. F., and McDaniel, L. R. 1988. Predicting stripe rust severity on winter wheat using an improved method for analyzing meteorological and rust data. Phytopathology 78:543-550.

Coakley, S. M., McDaniel, L. R., and Shaner, G. 1985. Model for predicting severity of Septoria tritici blotch on winter wheat. Phytopathology 75:1245-1251.

Cossette, F., and Miller, J. D. 1995. Phytotoxic effect of deoxynivalenol and Gibberella ear rot resistance of corn. Nat. Toxins 3:383-388.

Cowger, C., and Arrellano, C. 2010. Plump kernels with high deoxynivalenol linked to late Gibberella zeae infection and marginal disease conditions in winter wheat. Phytopathology 100:719-728.

Cowger, C., Patton-Özkurt, J., Brown-Guedira, G., and Perugini, L. 2009. Postanthesis moisture increased Fusarium head blight and deoxynivalenol levels in North Carolina winter wheat. Phytopathology 99:320-327.

Culler, M. D., Miller-Garvin, J. E., and Dill-Macky, R. 2007. Effect of extended irrigation and host resistance on deoxynivalenol accumulation in Fusariuminfected wheat. Plant Dis. 91:1464-1472.

Dalla Lana, F., Minyo, R., Thomison, P., Madden, L. V., and Paul, P. A. 2016. Weather patterns associated with Gibberella ear rot of corn in Ohio. In: APS Annu. Meet., Tampa, FL, U.S.A.

De Wolf, E., and Paul, P. A. 2014. Predicting mycotoxin contamination in wheat. Pages 248-257 in: Mycotoxin Reduction in Grain Chains. J. F. Leslie and A. F. Logrieco, eds. John Wiley \& Sons, Ltd., Chichester, UK.

De Wolf, E. D., Madden, L. V., and Lipps, P. E. 2003. Risk assessment models for wheat Fusarium head blight epidemics based on within-season weather data. Phytopathology 93:428-435.

Desjardins, A. E. 1996. Reduced virulence of trichothecene-nonproducing mutants of Gibberella zeae in wheat field tests. Mol. Plant-Microbe Interact. 9:775-781.

Desjardins, A. E. 2006. Fusarium Mycotoxins: Chemistry, Genetics, and Biology. American Phytopathological Society, St. Paul, MN, U.S.A.

Edite Bezerra da Rocha, M., Freire, F. C. O., Maia, F. E. F., Guedes, M. I. F., and Rondina, D. 2014. Mycotoxins and their effects on human and animal health. Food Control 36:159-165.

Foroud, N., and Eudes, F. 2009. Trichothecenes in cereal grains-An update. Int. J. Mol. Sci. 10:147-173.

Foroud, N. A., McCormick, S. P., MacMillan, T., Badea, A., Kendra, D. F., Ellis, B. E., and Eudes, F. 2012. Greenhouse studies reveal increased aggressiveness of emergent Canadian Fusarium graminearum chemotypes in wheat. Plant Dis. 96:1271-1279.

Francl, L. J., Madden, L. V., Rowe, R. C., and Riedel, R. M. 1990. Correlation of growing season environmental variables and the effect of early dying on potato yield. Phytopathology 80:425-432.

Gale, L. R., Ward, T. J., Balmas, V., and Kistler, H. C. 2007. Population subdivision of Fusarium graminearum sensu stricto in the Upper Midwestern United States. Phytopathology 97:1434-1439.

Hallen-Adams, H. E., Wenner, N., Kuldau, G. A., and Trail, F. 2011. Deoxynivalenol biosynthesis-related gene expression during wheat kernel colonization by Fusarium graminearum. Phytopathology 101:1091-1096.

Harris, L. J., Desjardins, A. E., Plattner, R. D., Nicholson, P., Butler, G., Young, J. C., Weston, G., Proctor, R. H., and Hohn, T. M. 1999. Possible role of trichothecene mycotoxins in virulence of Fusarium graminearum on maize. Plant Dis. 83:954-960.

Hart, L. P. 1984. Effect of kernel development and wet periods on production of deoxynivalenol in wheat infected with Gibberella zeae. Phytopathology 74: 1415-1418.

Hooker, D. C., and Schaafsma, A. W. 2005. Agronomic and environmental impacts on concentrations of deoxynivalenol and fumonisin B1 in corn across Ontario. Can. J. Plant Pathol. 27:347-356.

Hooker, D. C., Schaafsma, A. W., and Tamburic-Ilincic, L. 2002. Using weather variables pre- and post-heading to predict deoxynivalenol content in winter wheat. Plant Dis. 86:611-619.

Hope, R., Aldred, D., and Magan, N. 2005. Comparison of environmental profiles for growth and deoxynivalenol production by Fusarium culmorum and $F$. graminearum on wheat grain. Lett. Appl. Microbiol. 40:295-300.

Ismaiel, A., and Papenbrock, J. 2015. Mycotoxins: Producing fungi and mechanisms of phytotoxicity. Agriculture 5:492-537.

Khatibi, P. A., McMaster, N. J., Musser, R., and Schmale, D. G. 2014. Survey of mycotoxins in corn distillers' dried grains with solubles from seventy-eight ethanol plants in twelve States in the U.S. In 2011. Toxins (Basel) 6:1155-1168.

Koehler, B. 1959. Corn ear rots in Illinois. Bulletin 639. University of Illinois. https://www.ideals.illinois.edu/bitstream/handle/2142/13281/cornearrotsinillo0koeh. pdf? sequence $=1$

Kriss, A. B., Paul, P. A., and Madden, L. V. 2010. Relationship between yearly fluctuations in Fusarium head blight intensity and environmental variables: A window-pane analysis. Phytopathology 100:784-797.
Kriss, A. B., Paul, P. A., Xu, X., Nicholson, P., Doohan, F. M., Hornok, L., Rietini, A., Edwards, S. G., and Madden, L. V. 2012. Quantification of the relationship between the environment and Fusarium head blight, Fusarium pathogen density, and mycotoxins in winter wheat in Europe. Eur. J. Plant Pathol. 133: 975-993.

Kuhnem, P. R., Spolti, P., Del Ponte, E. M., Cummings, J. A., and Bergstrom, G. C. 2015. Trichothecene genotype composition of Fusarium graminearum not differentiated among isolates from maize stubble, maize ears, wheat spikes, and the atmosphere in New York. Phytopathology 105:695-699.

Llorens, A., Mateo, R., Hinojo, M. J., Valle-Algarra, F. M., and Jiménez, M. 2004 Influence of environmental factors on the biosynthesis of type B trichothecenes by isolates of Fusarium spp. from Spanish crops. Int. J. Food Microbiol. 94: 43-54.

Manstretta, V., Morcia, C., Terzi, V., and Rossi, V. 2016. Germination of Fusarium graminearum ascospores and wheat infection are affected by dry periods and by temperature and humidity during dry periods. Phytopathology 106:262-269.

Miller, J. D. 1994. Epidemiology of Fusarium ear diseases of cereals. Pages 19-33 in: Mycotoxins in Grain: Compounds Other Than Aflatoxin. J. D. Miller and H. L. Trenholm, eds. Eagan Press, St. Paul, MN, U.S.A.

Miller, S. S., Reid, L. M., and Harris, L. J. 2007. Colonization of maize silks by Fusarium graminearum, the causative organism of Gibberella ear rot. Can. J. Bot. 85:369-376.

Minyo, R. J., Geyer, A. B., Thomison, P. R., and Lohnes, D. G. 2015. 2015 Ohio Corn Performance Test. Ohio State University Extension/Ohio Agricultural Research \& Development Center, Columbus, OH, U.S.A. https://www.oardc.ohio-state.edu/ corntrials/CountryJournal2015.pdf

Minyo, R. J., Geyer, A. B., Thomison, P. R., and Lohnes, D. G. 2016. 2016 Ohio Corn Performance Test. Ohio State University Extension/Ohio Agricultural Research \& Development Center, Columbus, OH, U.S.A. https://www.oardc.ohio-state.edu/ corntrials/CountryJournal2016.pdf

Minyo, R. J., Geyer, A. B., Thomison, P. R., and Lohnes, D. G. 2017. 2017 Ohio Corn Performance Test. Ohio State University Extension/Ohio Agricultural Research \& Development Center, Columbus, OH, U.S.A. https://www.oardc.ohio-state.edu/ corntrials/CountryJournal2017.pdf

Minyo, R. J., Geyer, A. B., Thomison, P. R., and Lohnes, D. G. 2018. 2018 Ohio Corn Performance Test. Ohio State University Extension/Ohio Agricultural Research \& Development Center, Columbus, OH, U.S.A. https://www.oardc.ohio-state.edu/ corntrials/CountryJournal2018.pdf

Molitor, D., Baus, O., Hoffmann, L., and Beyer, M. 2016. Meteorological conditions determine the thermal-temporal position of the annual Botrytis bunch rot epidemic on Vitis vinifera L. cv. Riesling grapes. J. Int. Sci. Vigne Vin 50:231-244

Moraes, W. B., Schwarz, P. B., Madden, L. V., and Paul, P. A. 2018. Influence of temperature and relative humidity on mycotoxin production in wheat after Fusarium head blight symptom development. Pages 12-16. in: Proc. 2018 Natl. Fusarium Head Blight Forum, St. Louis, MO, U.S.A.

Mueller, D. S., Wise, K. A., Sisson, A. J., Allen, T. W., Bergstrom, G. C., Bosley, D. B., Bradley, C. A., Broders, K. D., Byamukama, E., Chilvers, M. I., Collins, A., Faske, T. R., Friskop, A. J., Heiniger, R. W., Hollier, C. A., Hooker, D. C., Isakeit, T., Jackson-Ziems, T. A., Jardine, D. J., Kelly, H. M., Kinzer, K., Koenning, S. R., Malvick, D. K. M., McMullen, M., Meyer, R. F., Paul, P. A., Robertson, A. E., Roth, G. W., Smith, D. L., Tande, C. A., Tenuta, A. U., Vincelli, P., and Warner, F. 2016. Corn yield loss estimates due to diseases in the United States and Ontario, Canada from 2012 to 2015. Plant Health Res. 17:211-222.

Munkvold, G. P. 2003. Epidemiology of Fusarium diseases and their mycotoxins in maize ears. Eur. J. Plant Pathol. 109:705-713.

Munkvold, G. P., and White, D. G., eds. 2016. Compendium of Corn Diseases, Fourth Ed. American Phytopathological Society, St. Paul, MN, U.S.A.

Papst, C., Utz, H. F., Melchinger, A. E., Eder, J., Magg, T., Klein, D., and Bohn, M 2001. Mycotoxins produced by Fusarium spp. in isogenic Bt vs. non-Bt maize hybrids under European corn borer pressure. Agron. J. 97:219-224.

Paul, P. A., Lipps, P. E., and Madden, L. V. 2006. Meta-analysis of regression coefficients for the relationship between Fusarium head blight and deoxynivalenol content of wheat. Phytopathology 96:951-961.

Paul, P. A., and Munkvold, G. P. 2005. Regression and artificial neural network modeling for the prediction of gray leaf spot of maize. Phytopathology 95 : 388-396.

Paulitz, T. C. 1996. Diurnal release of ascospores by Gibberella zeae in inoculated wheat plots. Plant Dis. 80:674-678.

Peiris, K. H. S., Pumphrey, M. O., Dong, Y., and Dowell, F. E. 2011. Fusarium head blight symptoms and mycotoxin levels in single kernels of infected wheat spikes. Cereal Chem. J. 88:291-295.

Pietravalle, S., Shaw, M. W., Parker, S. R., and van den Bosch, F. 2003. Modeling of relationships between weather and Septoria tritici epidemics on winter wheat: A critical approach. Phytopathology 93:1329-1339.

Pioneer. 2014. Pioneer Brand Products for Southern Indiana: 2014-2015. http:// www.compassagservices.com/wp-content/uploads/2015/05/14-2413-LP-trifoldproduct-chart10.pdf

Placinta, C. M., D'Mello, J. P. F., and Macdonald, A. M. C. 1999. A review of worldwide contamination of cereal grains and animal feed with Fusarium mycotoxins. Anim. Feed Sci. Technol. 78:21-37. 
Prenger, J. J., and Ling, P. P. 2001. Greenhouse condensation control: Understanding and using vapor pressure deficit (VPD). Ohio State University Extension Fact Sheet.

Proctor, R. H. 1995. Reduced virulence of Gibberella zeae caused by disruption of a trichothecene toxin biosynthetic gene. Mol. Plant-Microbe Interact. 8:593-601.

Puri, K. D., and Zhong, S. 2010. The 3ADON population of Fusarium graminearum found in North Dakota is more aggressive and produces a higher level of DON than the prevalent 15ADON population in spring wheat. Phytopathology 100:1007-1014.

Ramirez, M. L., Chulze, S., and Magan, N. 2006. Temperature and water activity effects on growth and temporal deoxynivalenol production by two Argentinean strains of Fusarium graminearum on irradiated wheat grain. Int. J. Food Microbiol. 106:291-296.

R Core Team. 2019. R: A Language and Environment for Statistical Computing. R Foundation for Statistical Computing, Vienna, Austria.

Reid, L. M., Mather, D. E., and Hamilton, R. I. 1996. Distribution of deoxynivalenol in Fusarium graminearum-infected maize ears. Phytopathology 86:110-114.

Reid, L. M., Mather, D. E., Hamilton, R. I., and Bolton, A. T. 1992. Genotypic differences in the resistance of maize silk to Fusarium graminearum. Can. J. Plant Pathol. 14:211-214.

Reid, L. M., Nicol, R. W., Ouellet, T., Savard, M., Miller, J. D., Young, J. C., Stewart, D. W., and Schaafsma, A. W. 1999. Interaction of Fusarium graminearum and $F$. moniliforme in maize ears: Disease progress, fungal biomass, and mycotoxin accumulation. Phytopathology 89:1028-1037.

Reid, L. M., and Sinha, R. C. 1998. Maize maturity and the development of Gibberella ear rot symptoms and deoxynivalenol after inoculation. Eur. J. Plant Pathol. 104:147-154.

Salgado, J. D., Wallhead, M., Madden, L. V., and Paul, P. A. 2011. Grain harvesting strategies to minimize grain quality losses due to Fusarium head blight in wheat. Plant Dis. 95:1448-1457.

Schaafsma, A. W. A. W., Limay-Rios, V., Paul, D. E., Miller, J. D., and David Miller, J. 2009. Mycotoxins in fuel ethanol co-products derived from maize: A mass balance for deoxynivalenol. J. Sci. Food Agric. 89:1574-1580.

Schmale, D. G., Wood-Jones, A. K., Cowger, C., Bergstrom, G. C., and Arellano, C. 2011. Trichothecene genotypes of Gibberella zeae from winter wheat fields in the eastern USA. Plant Pathol. 60:909-917.

Schmidt-Heydt, M., Parra, R., Geisen, R., and Magan, N. 2011. Modelling the relationship between environmental factors, transcriptional genes and deoxynivalenol mycotoxin production by strains of two Fusarium species. J. R. Soc. Interface 8:117-126.

Shah, D. A., De Wolf, E. D., Paul, P. A., and Madden, L. V. 2014. Predicting Fusarium head blight epidemics with boosted regression trees. Phytopathology 104:702-714.

Shah, D. A., De Wolf, E. D., Paul, P. A., and Madden, L. V. 2019a. Functional data analysis of weather variables linked to Fusarium head blight epidemics in the United States. Phytopathology 109:96-110.

Shah, D. A., Molineros, J. E., Paul, P. A., Willyerd, K. T., Madden, L. V., and De Wolf, E. D. 2013. Predicting Fusarium head blight epidemics with weatherdriven pre- and post-anthesis logistic regression models. Phytopathology 103: 906-919

Shah, D. A., Paul, P. A., De Wolf, E. D., and Madden, L. V. 2019b. Predicting plant disease epidemics from functionally represented weather series. Philos. Trans. R. Soc. B Biol. Sci. 374:20180273.

Simes, R. J. 1986. An improved Bonferroni procedure for multiple tests of significance. Biometrika 73:751-754.

Spolti, P., Del Ponte, E. M., Cummings, J. A., Dong, Y., and Bergstrom, G. C. 2014. Fitness attributes of Fusarium graminearum isolates from wheat in
New York possessing a 3-ADON or 15-ADON trichothecene genotype. Phytopathology 104:513-519.

Stull, R. 2011. Wet-bulb temperature from relative humidity and air temperature J. Appl. Meteorol. Climatol. 50:2267-2269.

Sutton, J. C. 1982. Epidemiology of wheat head blight and maize ear rot caused by Fusarium graminearum. Can. J. Plant Pathol. 4:195-209.

Sutton, J. C., Baliko, W., and Liu, H. J. 1980. Fungal colonization and zearalenone accumulation in maize ears injured by birds. Can. J. Plant Sci. 60:453-461.

Te Beest, D. E., Paveley, N. D., Shaw, M. W., and van den Bosch, F. 2008 Disease-weather relationships for powdery mildew and yellow rust on winter wheat. Phytopathology 98:609-617.

Thompson, M., and Raizada, M. 2018. Fungal pathogens of maize gaining free passage along the silk road. Pathogens 7:81

Tittlemier, S. A., Blagden, R., Chan, J., Roscoe, M., and Pleskach, K. 2020. A multi-year survey of mycotoxins and ergosterol in Canadian oats. Mycotoxin Res. 36:103-114.

USDA-FGIS. 2018. FGIS performance verified deoxynivalenol test kits. United States Department of Agriculture-Federal Grain Inspection Service. https:// www.gipsa.usda.gov/fgis/metheqp/GIPSA_Approved_Mycotoxin_Rapid_Test Kits.pdf

Valverde-Bogantes, E., Bianchini, A., Herr, J. R., Rose, D. J., Wegulo, S. N., and Hallen-Adams, H. E. 2019. Recent population changes of Fusarium head blight pathogens: Drivers and implications. Can. J. Plant Pathol. 16:1-15.

van der Fels-Klerx, H. J., and de Rijk, T. C. 2014. Performance evaluation of lateral flow immuno assay test kits for quantification of deoxynivalenol in wheat. Food Control 46:390-396.

Vigier, B., Reid, L. M., Dwyer, L. M., Stewart, D. W., Sinha, R. C., and Arnason, J. T. 2001. Maize resistance to Gibberella ear rot: Symptoms, deoxynivalenol, and yield. Can. J. Plant Pathol. 23:99-105.

Vogelgsang, S., Musa, T., Bänziger, I., Kägi, A., Bucheli, T., Wettstein, F., Pasquali, M., and Forrer, H.-R. 2017. Fusarium mycotoxins in Swiss wheat: A survey of growers' samples between 2007 and 2014 shows strong year and minor geographic effects. Toxins (Basel) 9:246.

Ward, T., Clear, R. M., Rooney, A. P., O’Donnell, K., Gaba, D., Patrick, S. Starkey, S. D., Gilbert, J., Geiser, D. M., and Nowicki, T. W. 2008. An adaptive evolutionary shift in Fusarium head blight pathogen populations is driving the rapid spread of more toxigenic Fusarium graminearum in North America. Fungal Genet. Biol. 45:473-484.

Wickham, H., Averick, M., Bryan, J., Chang, W., McGowan, L., François, R., Grolemund, G., Hayes, A., Henry, L., Hester, J., Kuhn, M., Pedersen, T., Miller, E., Bache, S., Müller, K., Ooms, J., Robinson, D., Seidel, D., Spinu, V., Takahashi, K., Vaughan, D., Wilke, C., Woo, K., and Yutani, H. 2019. Welcome to the Tidyverse. J. Open Source Softw. 4:1686.

Xu, X., Ma, L., and Hu, X. 2019. Overwintering of wheat stripe rust under field conditions in the northwestern regions of China. Plant Dis. 103:638-644.

Xu, X., Madden, L. V., and Edwards, S. G. 2014. Modeling the effects of environmental conditions on HT2 and T2 toxin accumulation in field oat grains. Phytopathology 104:57-66.

Xu, X., Madden, L. V., Edwards, S. G., Doohan, F. M., Moretti, A., Hornok, L., Nicholson, P., and Ritieni, A. 2013. Developing logistic models to relate the accumulation of DON associated with Fusarium head blight to climatic conditions in Europe. Eur. J. Plant Pathol. 137:689-706.

Zhang, Y., and Caupert, J. 2012. Survey of mycotoxins in U.S. distiller's dried grains with solubles from 2009 to 2011. J. Agric. Food Chem. 60:539-543.

Zhang, Y., Caupert, J., Imerman, P. M., Richard, J. L., and Shurson, G. C. 2009 The occurrence and concentration of mycotoxins in U.S. distillers dried grains with solubles. J. Agric. Food Chem. 57:9828-9837. 